\title{
Productivity and the age composition of
} WORK TEAMS:

EVIDENCE FROM THE ASSEMBLY LINE

Axel Börsch-Supan and Matthias Weiss

( mea-Mannheim Research Institute for the Economics of Aging 


\title{
Productivity and the age composition of work teams: Evidence from the assembly line*
}

\author{
Axel Börsch-Supan ${ }^{\dagger}$ and Matthias Weiss§
}

\begin{abstract}
This paper studies the relation between workers' age and their productivity in work teams. We explore a unique data set that combines data on errors occurring in the production process of a large car manufacturer with detailed information on the personal characteristics of workers responsible for the errors. We do not find evidence that productivity declines with age.
\end{abstract}

JEL codes: J24, J14, D24

Keywords: Age-Productivity Profiles

* We are grateful to Melanie Lührmann and Jürgen Maurer for valuable comments and suggestions. Verena Arendt, Melanie Gräsle, Simon Hilpert, and Finn Körner provided excellent research assistance. Funding by the State Baden-Württemberg, the Gesamtverband der Deutschen Versicherungswirtschaft, and the Hans-Böckler-Stiftung is gratefully acknowledged. We are especially grateful to the Daimler truck assembly plant in Wörth, Germany. Without the great support from our contact persons in the different departments of the plant and from the side of the management and the works council, this project would not have been possible.

$\dagger$ MEA, Universität Mannheim, Germany and NBER.

§ Corresponding author. MEA, Universität Mannheim, Germany, E-Mail: weiss@mea.unimannheim.de. 


\section{Introduction}

The age composition in most of the developed world has been shifting towards older age groups for more than 100 years now. The steady population aging has intensified dramatically in consequence of the direct succession of the post war "baby boom" and the "baby bust" of the late 1960s. This accelerated aging process will have farreaching economic consequences. Most prominent in the public discussion are the consequences for the pay-as-you-go financed social security systems. But before the babyboomers are going to retire (with their pensions having to be financed by the babybusters), extensive changes are to be expected on labor markets and in production: In Germany, e.g., the share of workers aged 55 years and older will more than double from $12 \%$ in 2005 to almost $25 \%$ in 2035 . In view of this looming evolution, it is important to better understand the relation between workers' age and their labor productivity.

Estimating age-productivity profiles has been on the agenda of labor economists for a long time. The main problem with estimating age-productivity profiles is that it requires a valid measure for productivity. There are many studies in occupational medicine, cognitive psychology, and gerontology that look at how different abilities and skills of humans evolve over their life-cycle. They look at muscle strength, sight, retentiveness, the functioning of lungs, kidney, and the heart, and many other measurable indicators. More or less concordantly, they find that from the age of 25 onwards, physical and mental fitness are deteriorating. ${ }^{1}$ But there is certainly more to labor productivity than muscle strength, sight, and cognitive ability. Experience plays a role and is increasing with age. Hence, there is a need for more direct measures of productivity. Regarding the measurement of productivity, the existing literature can be broadly divided into four branches: (i) studies relating plant level productivity to the age of the plants' employees, ${ }^{2}$ (ii) studies using individual's wages as a productivity measure, ${ }^{3}$ (iii) studies using interviews of managers on their employ-

1 This literature is surveyed in Skirbekk (2004) and Börsch-Supan, Düzgün, and Weiss (2005).

2 E.g., Hellerstein, and Neumark (1995) and (2004), Hellerstein, Neumark, and Troske (1999), Haltiwanger, Lane, and Spletzer (1999) and (2007), Crépon, Deniau, and Pérez-Duarte (2002), Aubert and Crépon (2004), Grund, Westergård-Nielsen (2005), Ilmakunnas and Maliranta (2005), Malmberg, Lindh, and Halvarsson (2005), and Prskawetz, Mahlberg, Skirbekk, Freund, Dworak, Lindh, Malmberg, Jans, Nordström, and Andersson (2005).

3 E.g., Kotlikoff and Wise (1989), Kotlikoff and Gokhale (1992), and Laitner and Stolyarov (2005). 
ees' performance, ${ }^{4}$ and (iv) studies using direct measures of individual productivity like, e.g., the number and quality of publications in academic research, ${ }^{5}$ the value of artists' paintings (in terms of auction proceeds), ${ }^{6}$ or performance in sports and chess. $^{7}$

These different approaches all have their vices and virtues. Plant level productivity can be measured easily and reliably but the level of aggregation is quite high when the goal is to study the relation between productivity and age. Furthermore, the age structure of firms is probably not exogenous.

Wages are the obvious productivity measure in many applications (returns to schooling, inter-personal comparisons, etc.) but when it comes to age profiles, the problem is that in many occupations, wages increase with age and/or seniority independently of productivity. Wage decreases are extremely rare. ${ }^{8}$ Therefore, Kotlikoff and Wise (1989) look at earnings of insurance salesmen whose wages are proportional to the number of insurance contracts they sell.

Supervisors' assessments are problematic as they might reflect prejudices about age productivity profiles.

The studies subsumed as approach (iv) are able to measure productivity relatively exactly. Therefore, they can estimate age-productivity profiles quite precisely. But the occupations where this approach is feasible are rare and particular so that the results can hardly be generalized.

In addition, approaches (ii) through (iv) cannot take into account the fact that workers often work in teams and thereby affect one another's productivity. More specifically, if, e.g., older workers devote some of their working time to helping younger workers, the individual approach will underestimate older workers' productivity. Related aspects are workers' contributions to their team's work climate or how they deal with hectic situations (which again affects the productivity of the entire team).

In this paper, we follow a new approach: We look at productivity at the level of work teams. This

4 E.g., Medoff and Abraham (1980), Hunter and Hunter (1984), McEvoy and Cascio (1989), Salthouse and Maurer (1996), and Schneider and Stein (2006).

5 Jones (2005) and Weinberg and Galenson (2005).

6 Galenson and Weinberg (2000) and (20001), and Galenson (2005).

7 Fair (1994), (2005a), and (2005b).

8 Lazear (1979) and (1981) explains the increasing age-earning profiles with incentive effects. Loewenstein and Sicherman (1991) and Frank and Hutchens (1993) show in experiments that workers have a preference for increasing wage profiles and explain this with loss aversion and problems of self-control. 
takes into account the individual worker’s contribution to her co-workers’ productivity.

\section{The data}

\subsection{Our productivity measure and main explanatory variables}

We exploit a unique data set that we have compiled from a truck assembly plant of the German car manufacturer Daimler AG. At this plant, trucks are assembled by work teams on an assembly line. The quantity of output is determined by the speed of the assembly line. If work teams differ in productivity, this is not going to show up in differences in the quantity of output because the assembly line has the same speed for all teams. But production quality differs across work teams as they can make errors. Variation in productivity thus becomes manifest only in variation in production errors.

These errors are recorded by a "quality inspector" at the end of the assembly line. The quality inspector is able to assign every error to the work place where it happened. At any time, there is exactly one work team at any work place. In addition, every error is given a weight (between 5 and 95) that specifies the severity of the error. From this record of errors, we know which team has made how many errors of which severity on any day in 2003 through 2006. We observe 3824 workers in 100 work teams at 50 work places on 973 days. The number of teams is double the number of work places because on every day, there is an early and a late shift. Our productivity measure is the sum of errors per team per day where the errors are rated with their respective weights. E.g., if a team with 7 workers makes two errors on a day with weights 5 and 30, our (inverse) productivity measure for this team for this day takes the value 35 .

The information on errors is matched with personnel data that inform us about the daily composition of the work teams, personal characteristics of the workers such as age, sex, education, nationality, job tenure, and whether or not a worker is in her regular team.

In addition, we have data on the daily production plan which gives us information on the work load. 


\subsection{Matching error data and personnel data}

The error data contain information on the work team where the error occurred. This information allows matching the error data with personnel data However, not every error in our data set can be related to one single work team. For many errors, the quality inspector specified a locus delicti an area of the assembly line that encompasses the work places of several work teams. In other cases, the quality inspector was able to unambiguously specify the work place but not whether the error occurred during the early shift or the late shift. In these ambiguous cases, we created an observation for each possible outcome and attributed weights to these observations according to their probability. For example, if an error is uniquely attributed to a work place but cannot be related to early or late shift, we create one observation where we attribute the error to the team that worked at this work place in the early shift and an additional observation where we attribute the error to the team that worked at this work place in the late shift. Each of these two observations enters our regressions with weight 0.5. Figure 1 shows the distribution of these observation weights. Roughly one half of the observations have a weight equal to 1 . The observation weight can have so many different values because the observation unit is a team-day. Suppose, e.g., there are two errors that were potentially made in team $j$, one with probability $1 / 2$ and one with probability $1 / 3$. In this case, we create three observations, one, where team $j$ makes no error (probability $(1-1 / 2) \cdot(1-1 / 3)=1 / 3)$, one with 1 error (probability $1 / 2 \cdot(1-1 / 3)+1 / 3 \cdot(1-1 / 2)=1 / 2)$, and one with 2 errors (probability $1 / 2 \cdot 1 / 3=1 / 6$ ). As work teams in our sample make up to eight errors per day, the number of possible values for the observation weight is large. Obviously, the observation weights must sum to 1 for each team-day.

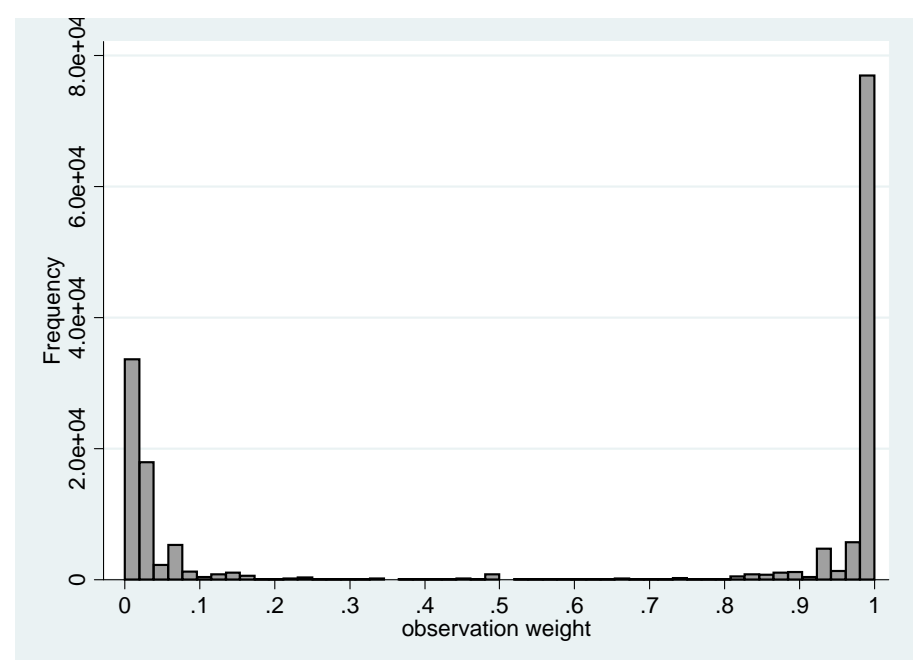

Figure 1: Distribution of observation weights 


\subsection{Some descriptives}

As the data set we use is quite unique, this section gives a brief description of the main variables we use. Table 2 in Appendix A reports descriptive statistics of all variables used in the paper.

\section{Errors}

We observe 8564 errors in 100 teams on 973 days. The distribution of error weights (only for those days and teams for which we observe errors) is given in Figure 2.

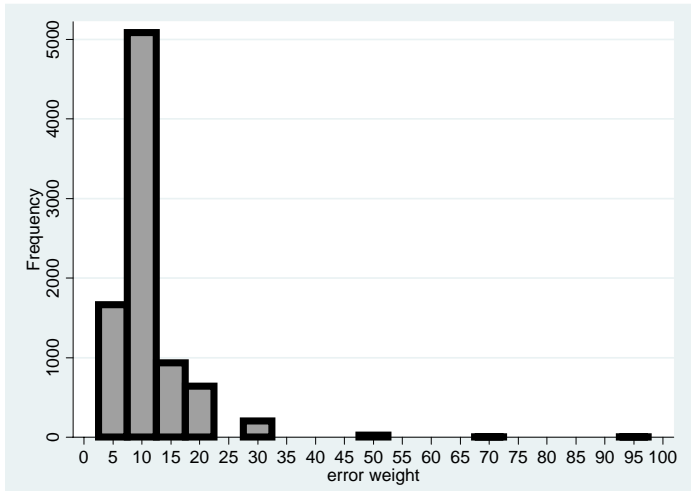

Figure 2: Distribution of error weights conditional on the observation errors

Age

The age composition in the plant is fairly representative for the German workforce in that workers older than 55 are rare. Figure 3 shows the age distribution in the plant (black) in comparison to the age distribution of the German population (grey).

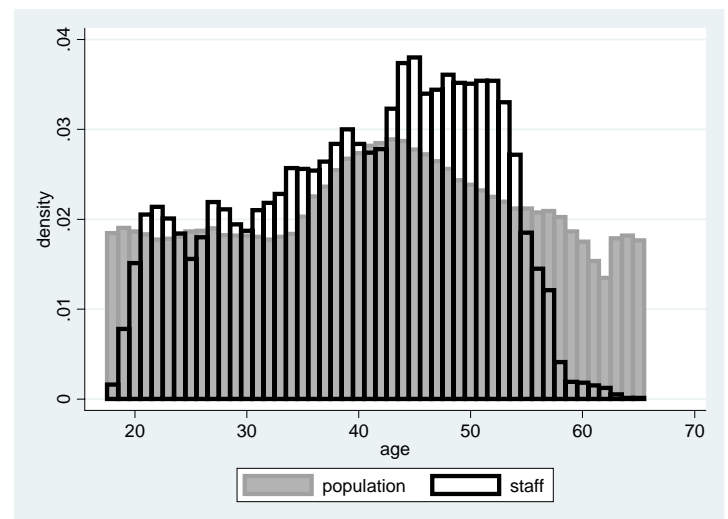

Figure 3: Age distribution in the plant (black) and in Germany (grey)

People younger than twenty are underrepresented because they are still in education or training. The share of workers aged 55 and over is low at the assembly line because many are already retired or have moved to better jobs. Figure 4 shows the 
distribution of average age of work teams which constitute the observation unit in our regression analysis.

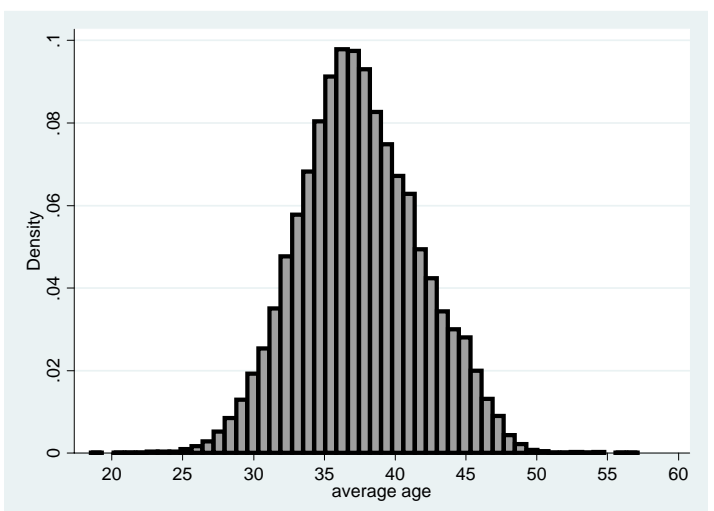

Figure 4: Distribution of average age of work teams

\section{Job tenure}

In addition to age, we have information on workers' job tenure. Job tenure increases with age but the two variables are not perfectly correlated as workers are hired at different ages. The distribution of job tenure in the plant is shown in Figure 5. The spikes show hiring waves roughly every 5 to 10 years, the most recent having been just within the observation period (at job tenure $=0$ ).

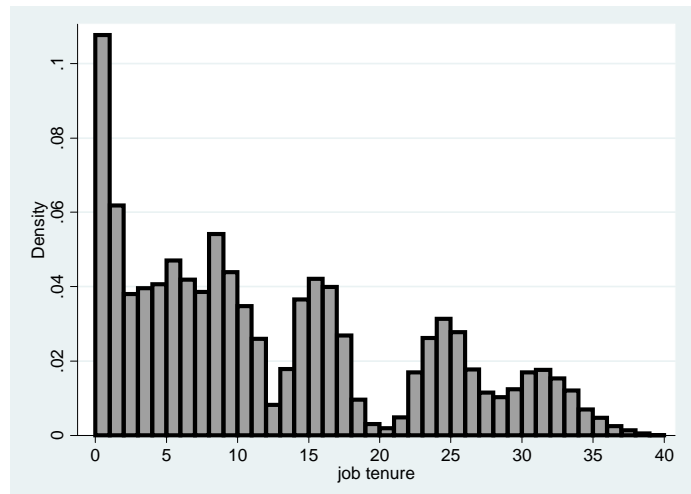

Figure 5: Distribution of job tenure in the plant

The distribution of average job tenure in work teams in Figure 6 shows that at hiring waves, the newly hired workers have been spread evenly over existing work teams as the histogram of average job tenure does not exhibit any comparable spikes. 


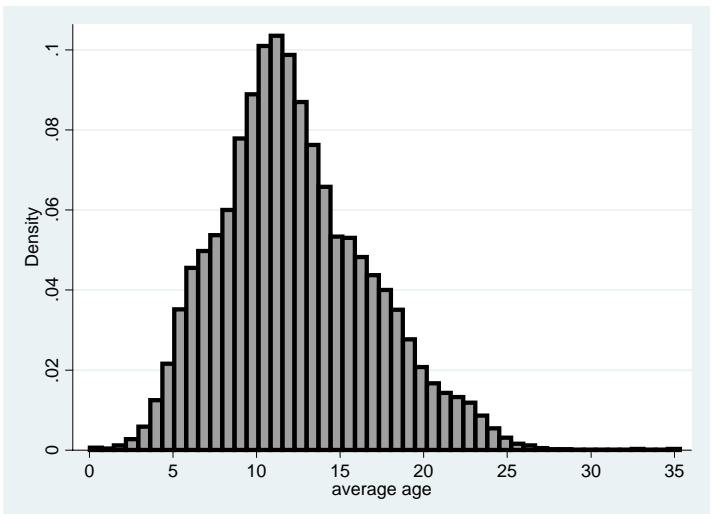

Figure 6: Distribution of average job tenure of work teams

Figure 7 shows the relation between age and job tenure in the plant. For any individual worker, age and job tenure are perfectly correlated over time, but as workers are hired at different ages, the overall correlation (over time and across workers) is "only" 0.79 .

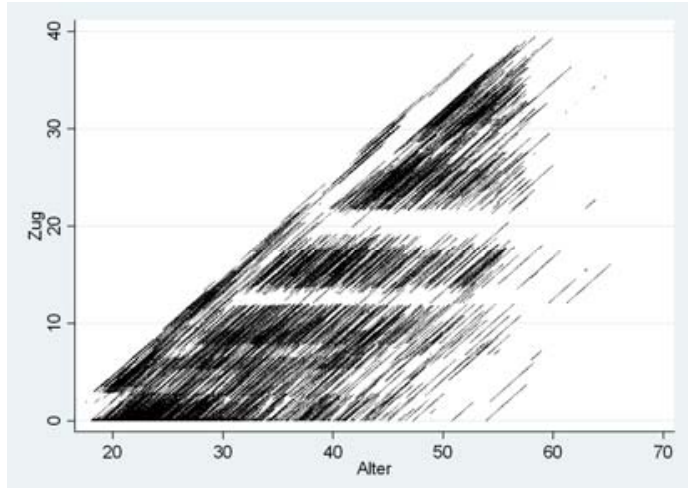

Figure 7: Scatter plot of job tenure (vertical axis) vs. age (horizontal axis)

The relation is tighter at the team level (see Figure 8).

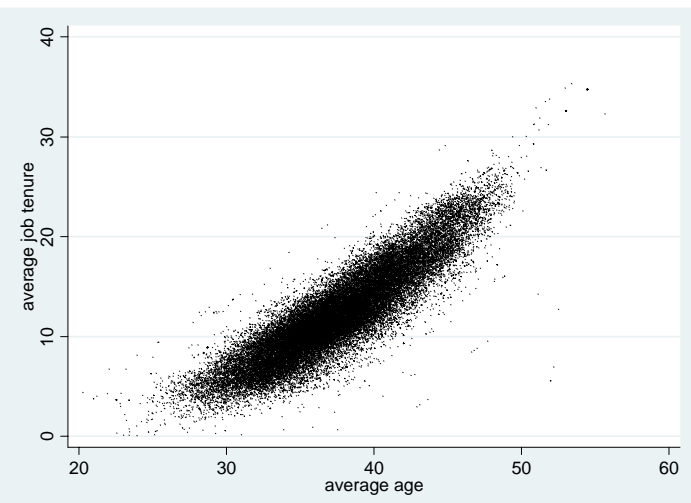

Figure 8: Scatter plot of average job tenure (vertical axis) vs. average age (horizontal axis) of work teams 


\section{Team size}

The size of work teams varies between 4 and 35 workers. 90\% of work teams have between 8 and 21 members (see Figure 9). The average team size is 14 .

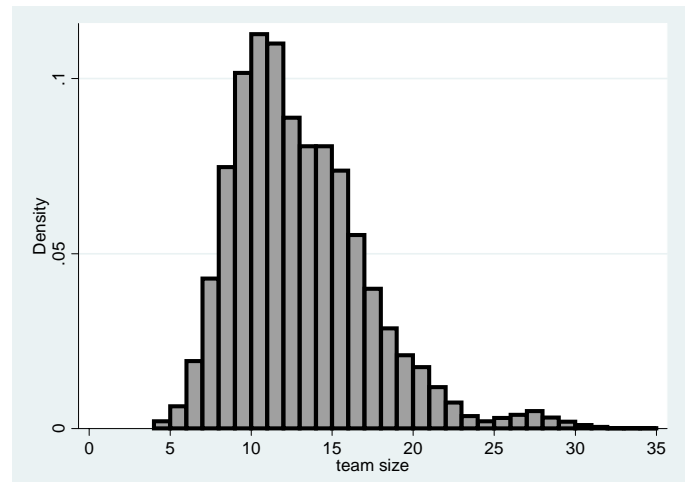

Figure 9: Distribution of team size in the plant

\section{Sex}

The share of women in the plant is $3.4 \%$. In $71 \%$ of all work teams, there are only men. In the other $29 \%$ of teams, women's share is $10.9 \%$ on average. Within the sample period, the female share has increased from $2.8 \%$ in 2003 to $3.6 \%$ in 2006 .

\section{Nationality}

The composition of the personnel with respect to nationality is given in the following table:

\begin{tabular}{ccccc}
\hline nationality & German & French & Turkish & other \\
\hline share & $65.3 \%$ & $26.0 \%$ & $4.1 \%$ & $4.6 \%$ \\
\hline
\end{tabular}

\section{Workload}

The production program and thereby the daily volume of work for every team varies over time. The required number of workers does not always exactly match the actual manning. We have daily information on the actual volume of work (measured in the number of required workers) and on actual manning for every day and every team. We use the percentage deviation of actual volume of work from actual manning as a measure of excess workload per worker. Figure 10 shows that the variation in excess workload is substantial. 


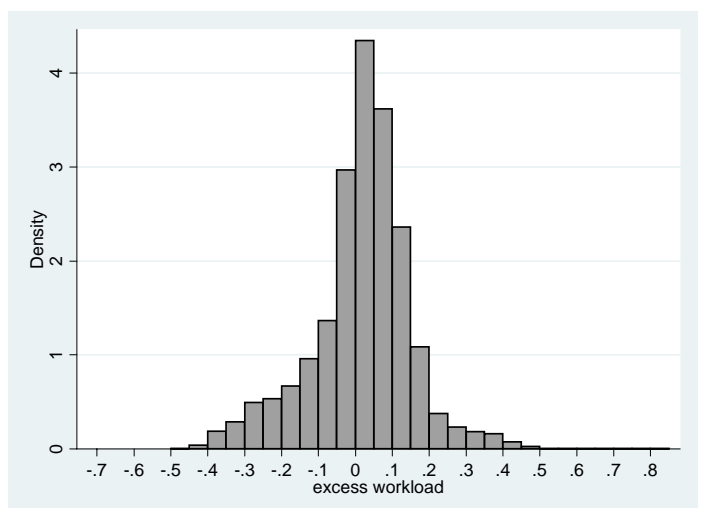

Figure 10: Distribution of excess work load (as a share of actual manning)

\section{External workers}

Each worker is assigned to one team as her "regular" team. But—due to fluctuations in team composition and workload-workers work outside their regular team $6 \%$ of the time on average. Some workers are explicitly trained for "team hopping" in order to stand in wherever needed. Figure 11 displays the distribution over time and across work teams of the share of workers external to the work team.

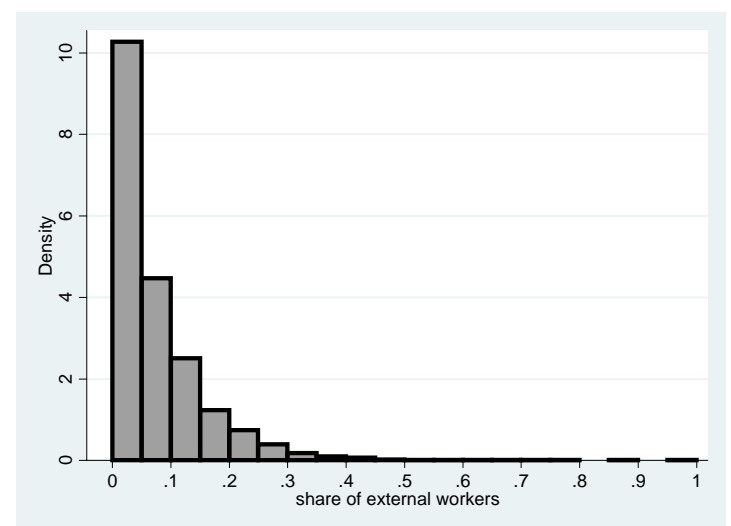

Figure 11: Distribution of the share of workers external to the work team

\section{Fluctuation}

The composition of work teams varies considerably over time. These fluctuations are due to vacation, sickness and-most importantly-due to compensatory time off for extra hours worked. Workers' contracts involve 7.5 hours per day while the assembly line runs 8 hours per work shift, so that workers accumulate one half hour overtime per day. Consequently, they can take every $16^{\text {th }}$ day off. This means that in a team of 16 workers, on an average day, one worker is absent due to compensatory time off. Another source of variation is given by the variation in workload. In order to buffer these fluctuations, each work team has about $20 \%$ more members than are needed on a regular day, because on average about $24 \%$ of the workers are absent 
due to sickness $(6 \%)$, vacation $(12 \%)$ or compensatory time off for extra hours worked (6\%). In addition, there is a pool of especially qualified workers who can fill in for absent workers. Furthermore, sometimes workers switch from their regular work team to another one if need be. Figure 10 displays a variable of fluctuation that we use in our regression analysis. This variable is constructed as the number of consecutive days without change in the composition of the work team. As we are interested in the effects of fluctuation on productivity, we only consider changes that concern workers who do not regularly belong to the team. We do not consider changes within the regular team as we think that these daily changes should not affect communication or team work as within the regular work team, workers are used to working together in all possible constellations. A value of 4 of our variable means thus that in the four preceding days, no external worker joined or left the work team. Figure 12 shows that the team composition usually changes from day to day.

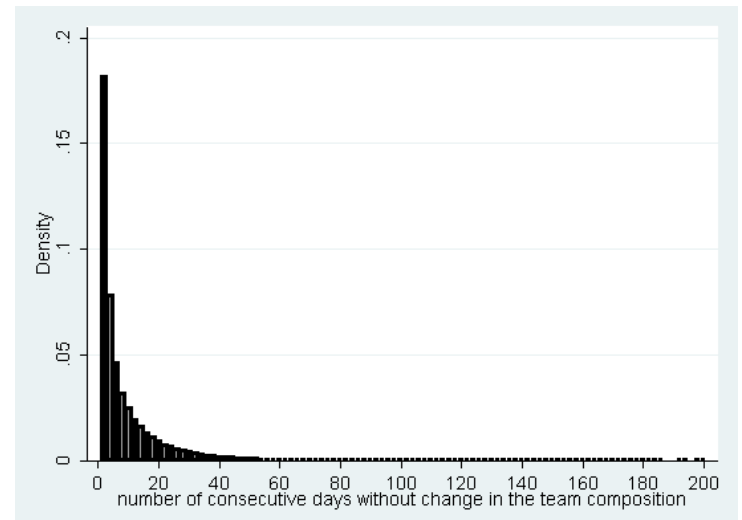

Figure 12: Distribution of the number of consecutive days without change in the team composition

\section{Identification}

In this section, we explain our identification strategy. Studies on the relation between age and productivity are potentially afflicted with the following problems:

- How can productivity be measured reliably? How can the productivity of different observation units be made comparable?

- How can we make sure that the variation in age that our estimates are based on is exogenous? 
- How can we deal with potential sample selection bias in the presence of early retirement?

- How can we distinguish age effects from cohort effects?

This section explains how we deal with these potential problems.

\subsection{Measuring productivity}

Measurement of productivity is difficult. The value added of a worker or a work team is usually not observed. And if the value added is observable, it is often not comparable across workers or work teams.

We measure productivity in the assembly process of a truck assembly plant. As the quantity of output per worker per day is given by the speed of the assembly line (which is the same for all workers), the only thing that distinguishes more productive workers from less productive workers is the number of production errors they make. The number and severity of errors are thus the ideal productivity measure in this context.

Errors are observed at the level of work teams. Thus, our productivity measure takes into account the individual workers' contribution to their co-workers' productivity. This is important if older workers contributions are larger. In that case, looking at individual level productivity underestimates older workers' productivity. Examples for older workers' contribution to their team's productivity are the instruction of younger workers, ${ }^{9}$ being relaxed in tense, hectic situations, contributing positively to the work climate, etc.

Are errors that occur at different places on the assembly line comparable? In some sense, they are because every error is given a severity weight. But still, a comparison across workplaces is probably unfair as some tasks are more error-prone than others. We control for this by using work team fixed effects. In other words, to identify our coefficients, we only use variation over time within work teams where the tasks are homogeneous.

\subsection{Exogeneity of variations in age}

\footnotetext{
${ }^{9}$ While an older worker helps a younger worker, the older worker's productivity is zero as she is not producing anything at that time. But the contribution to the work team's productivity is clearly positive.
} 
Studies on age and productivity that use plants as units of observation generally suffer from the problem that the age composition of plants is endogenous. Studies on individuals or work teams within plants potentially suffer from the same problem if age affects the assignment of workers to tasks. (If older workers are systematically assigned to easier tasks, their productivity may be overestimated.)

We observe productivity (errors) on the level of work teams. The allocation of workers across work teams (i.e., work places) may be endogenous. But the variation across work teams is not used in our estimation as we include work team fixed effects. The variation in the age composition within work teams over time-which we use to identify our estimates - is exogenous. From the responsible managers in the plant, we know that the fluctuation within work teams over time (which results from sick leave, vacation, and compensatory time off for extra hours worked) does not leave any room for optimization. The fluctuation within teams has two components: The team composition changes from day to day as some workers call in sick and others return from vacation. This day-to-day fluctuation within the core team is random and not the result of any optimization. The second component of fluctuation is the employment of so-called "team hoppers". In cases where the workers of the core team are too few, the vacancies are filled randomly from a pool of "team hoppers". Thus, we conclude, that the variation in the age composition that we use in our estimation is exogenous.

\subsection{Sample selection bias}

One recurrent criticism of studies on age-productivity profiles is that-due to sample selection bias-they overestimate the productivity of older workers. In fact, workers older than 55 years are underrepresented in the workforce. The obvious suspicion is that the remaining workers are a positive selection. The less motivated, less healthy workers probably retire earlier.

In our paper, we are able to correct for this potential bias in two ways: A Heckmanstyle selection correction model and worker fixed effects. The common problem with the correction for sample selection is that-by definition-we usually do not have information on those subjects who are not in the sample. As our sample covers several years, we do have information on those workers who enter or exit the sample within these three years. This enables us to estimate a Heckman-style selection correction model.

As our observation unit in the regression is a work team while selection into the 
sample is an individual phenomenon, we have to aggregate individual Mills ratios to team Mills ratios (see Appendix C).

In addition, selection into (and out of) our sample is more complex than selection out of the workforce of an entire plant or economy. Our sample consists only of workers on the assembly line. Even the foremen are not included. Workers who leave our sample before the age of 65 may retire early (possible because they are less motivated or less healthy than those who remain) or they may be promoted to jobs off the assembly line (possible because the performed better than those who remain). We therefore constructed different Mills ratios for younger workers (who are more likely to leave the sample for jobs off the assembly line) and for older workers (who are more likely to leave the sample for early retirement (see Appendix C for details).

A second possibility to correct for non-random sample selection is to include worker fixed effects. This is possible if worker-days are the observation unit and if-over time-workers move across work teams.

\subsection{Age vs. cohort effects}

A common problem in estimating age effects (be it on productivity, on consumption, savings or other variables) is that in a cross section of individuals, age effects are indistinguishable from cohort effects (at least without strong assumptions on the functional form). In a panel, where each cohort is observed at different ages, the distinction becomes possible. However, as individuals are observed over time, the potential existence of time effects may be confounded with age effects. From discussions with the plant managers, we conclude, that time effects do not play any role in our sample as there have not been any changes in technology or organization that could affect our productivity measure during the four years of our sample period.

\section{Results}

\subsection{Regressions on the team level}

This section reports results on the relation between workers' age and the number and severity of errors made in the truck assemble process. As explained in Section 2.1 , our (inverse) productivity measure is the weighted sum of errors per team per 
day where each error is given a weight according to its severity. Errors are observed daily at the team level. Thus, the observation unit in the regressions is a team day. We observe 3824 workers in 100 work teams on 973 days. As-along the assembly line-work places differ quite substantially and the allocation of workers to these work places and to early vs. late shift may be endogenous, we control for work team fixed effects. Only the day-to-day variation is used to identify our estimates. ${ }^{10}$ This variation results from fluctuations in the work team composition due to vacation, sickness and-most importantly-due to compensatory time off for extra hours worked (see Section 2.3). From discussions with managers at the plant on how they replace missing workers, we conclude that this variation is truly exogenous. There is no optimization taking place at this level.

In order to allow for non-linear age effects, we use a piecewise linear specification (5year splines). We also tried other specifications (polynomials, dummies for 5 -year age groups. The results are robust with respect to these different specifications.

As explained in Section 2.2, we have artificially inflated the error data set in order to be able to uniquely match the error data with the personnel data. We have assigned observation weights to these additional observations such that for each team-day, the observation weights sum to 1 . We use these weights in the regression. The reported numbers of observations refer to the non-inflated data set (and are equal to the sum of error weights).

The left column of Table 1 shows the results of our baseline regression. We also include a number of interactions with average team age. Therefore, the coefficients on the age splines cannot be interpreted as marginal effects. The estimated marginal effects including the interaction effects are reported in Table B.1 in Appendix B. The upper left chart in Figure 13 displays the (inverse) age productivity profile of work teams that results from the estimation. The weighted sum of errors per day increases up to an average age of 30 years and stabilizes thereafter. Column 2 of Table 1 and the upper right chart in Figure 13 display the results of a regression where we correct for possible sample selection bias using a Heckman-style approach (see Appendix C). Figure 13 shows that the slight decrease of errors with age between average age 30 and 45 turns into a slight increase. This finding indicates that workers who remain in the sample are indeed a positive selection. But the decrease in errors after average age 45 remains.

10 We also tried work place fixed effects, thereby using the variation over work shifts in addition the variation over time. The results are very similar. 
Table 1: Regression results: sum of error weights (team level)

\begin{tabular}{|c|c|c|c|c|c|c|}
\hline & \multicolumn{2}{|c|}{ baseline specification } & \multicolumn{2}{|c|}{$\begin{array}{l}\text { correcting for } \\
\text { sample selection }\end{array}$} & \multicolumn{2}{|c|}{$\begin{array}{l}\text { correcting for selection } \\
\text { controlling for job tenure }\end{array}$} \\
\hline \multicolumn{7}{|l|}{ age splines } \\
\hline $20-25$ years & 5.75 & $(0.000)$ & 6.10 & $(0.000)$ & 8.71 & $(0.000)$ \\
\hline $25-30$ years & 5.15 & $(0.000)$ & 5.50 & $(0.000)$ & 6.08 & $(0.000)$ \\
\hline $30-35$ years & 4.87 & $(0.000)$ & 5.22 & $(0.000)$ & 5.66 & $(0.000)$ \\
\hline $35-40$ years & 4.88 & $(0.000)$ & 5.21 & $(0.000)$ & 5.60 & $(0.000)$ \\
\hline $40-45$ years & 4.88 & $(0.000)$ & 5.19 & $(0.000)$ & 5.64 & $(0.000)$ \\
\hline $45-50$ years & 4.45 & $(0.000)$ & 4.77 & $(0.000)$ & 5.48 & $(0.000)$ \\
\hline $50-55$ years & 5.61 & $(0.000)$ & 5.83 & $(0.000)$ & 8.27 & $(0.000)$ \\
\hline \multicolumn{7}{|l|}{ job tenure splines } \\
\hline $0-4$ years & & & & & -1.57 & $(0.000)$ \\
\hline $4-8$ years & & & & & 0.006450 & $(0.853)$ \\
\hline $8-12$ years & & & & & -0.0965 & $(0.000)$ \\
\hline $12-16$ years & & & & & 0.0788 & $(0.000)$ \\
\hline $16-20$ years & & & & & -1.73 & $(0.000)$ \\
\hline $20-24$ years & & & & & -0.209 & $(0.000)$ \\
\hline $24-28$ years & & & & & -0.971 & $(0.000)$ \\
\hline $28-32$ years & & & & & -4.31 & $(0.042)$ \\
\hline \multicolumn{7}{|l|}{ control variables } \\
\hline schooling years & 2.49 & $(0.000)$ & 2.78 & $(0.000)$ & 2.89 & $(0.000)$ \\
\hline car specific educ & -5.42 & $(0.000)$ & -3.39 & $(0.010)$ & -2.46 & $(0.078)$ \\
\hline tech spec. educ & 0.517 & $(0.716)$ & 2.07 & $(0.143)$ & 3.76 & $(0.010)$ \\
\hline female & 23.2 & $(0.000)$ & 21.8 & $(0.000)$ & 23.9 & $(0.000)$ \\
\hline external & -0.673 & $(0.667)$ & -2.13 & $(0.182)$ & -2.33 & $(0.145)$ \\
\hline team size & 0.357 & $(0.000)$ & 0.125 & $(0.052)$ & 0.094 & $(0.145)$ \\
\hline$(\text { team size })^{2}$ & -0.00541 & $(0.000)$ & -0.00587 & $(0.000)$ & -0.00544 & $(0.000)$ \\
\hline late shift & -0.0743 & $(0.766)$ & -0.0318 & $(0.899)$ & -0.150 & $(0.952)$ \\
\hline days w/o change & 0.0327 & $(0.001)$ & 0.0342 & $(0.000)$ & 0.0352 & $(0.000)$ \\
\hline${\text { (days w/o change })^{2}}^{2}$ & -0.000043 & $(0.026)$ & -0.000048 & $5(0.012)$ & -0.000049 & $4(0.010)$ \\
\hline workload & 2.14 & $(0.002)$ & 4.38 & $(0.000)$ & 2.66 & $(0.050)$ \\
\hline$(\text { workload })^{2}$ & -0.390 & $(0.004)$ & -1.68 & $(0.001)$ & -1.74 & $(0.001)$ \\
\hline tryout Axor & -3.75 & $(0.000)$ & -3.83 & $(0.001)$ & -3.70 & $(0.000)$ \\
\hline tryout Atego & 2.51 & $(0.000)$ & 2.44 & $(0.000)$ & 2.48 & $(0.000)$ \\
\hline French & -6.09 & $(0.018)$ & -6.88 & $(0.007)$ & -3.36 & $(0.202)$ \\
\hline German & -10.9 & $(0.000)$ & -10.4 & $(0.000)$ & -6.01 & $(0.011)$ \\
\hline Turkish & -9.53 & $(0.008)$ & -5.85 & $(0.103)$ & -0.719 & $(0.842)$ \\
\hline temperature & 0.191 & $(0.000)$ & 0.164 & $(0.000)$ & 0.160 & $(0.000)$ \\
\hline temperature ${ }^{2}$ & -0.00545 & $(0.000)$ & -0.00559 & $(0.000)$ & -0.00547 & $(0.000)$ \\
\hline humidity & -0.137 & $(0.000)$ & -0.139 & $(0.000)$ & -0.142 & $(0.000)$ \\
\hline hours of sunshine & -0.0517 & $(0.273)$ & -0.363 & $(0.454)$ & -0.0387 & $(0.411)$ \\
\hline rainfall & 0.517 & $(0.000)$ & 0.513 & $(0.000)$ & 0.512 & $(0.000)$ \\
\hline air pressure & 0.0515 & $(0.006)$ & 0.0502 & $(0.007)$ & 0.0526 & $(0.005)$ \\
\hline Monday & 9.21 & $(0.000)$ & 8.14 & $(0.000)$ & 8.00 & $(0.000)$ \\
\hline Tuesday & 8.29 & $(0.000)$ & 7.21 & $(0.000)$ & 7.03 & $(0.000)$ \\
\hline Wednesday & 13.88 & $(0.000)$ & 12.8 & $(0.000)$ & 12.6 & $(0.000)$ \\
\hline Thursday & 8.99 & $(0.000)$ & 7.90 & $(0.000)$ & 7.73 & $(0.000)$ \\
\hline Friday & 12.8 & $(0.000)$ & 11.7 & $(0.000)$ & 11.5 & $(0.000)$ \\
\hline
\end{tabular}


In column 3 of Table 1, we control for average job tenure in the work team. The effect of age on productivity (i.e. errors) can now be decomposed in an "experience effect" and a "pure age effect". ${ }^{11}$ As can be seen in the lower left chart of Figure 13, the "pure age effect" is clearly positive. Older work teams make more errors if job tenure is held constant.

Table 1 cont'd: Regression results: sum of error weights (team level)

\begin{tabular}{|c|c|c|c|c|c|c|}
\hline dependent variable & sum of err & ror weights & & & & \\
\hline & baseline $\mathrm{sp}$ & pecification & $\begin{array}{l}\text { correcting } \\
\text { sample sel }\end{array}$ & $\begin{array}{l}\text { for } \\
\text { lection }\end{array}$ & $\begin{array}{l}\text { correcting } \\
\text { controlling }\end{array}$ & $\begin{array}{l}\text { for selection } \\
\mathrm{g} \text { for job tenure }\end{array}$ \\
\hline interactions of age & with... & & & & & \\
\hline schooling years & -0.0661 & $(0.000)$ & -0.0708 & $(0.000)$ & -0.0744 & $(0.000)$ \\
\hline car specific educ & 0.145 & $(0.000)$ & 0.0986 & $(0.005)$ & 0.0851 & $(0.022)$ \\
\hline tech spec. educ & -0.0195 & $(0.606)$ & -0.0543 & $(0.151)$ & -0.0905 & $(0.020)$ \\
\hline female & -0.614 & $(0.000)$ & -0.601 & $(0.000)$ & -0.658 & $(0.000)$ \\
\hline external & 0.0197 & (0.633) & 0.0274 & $(0.515)$ & 0.0334 & $(0.428)$ \\
\hline team size & 0.0197 & (0.933) & 0.00533 & $(0.001)$ & 0.00569 & $(0.000)$ \\
\hline late shift & -0.000856 & $(0.897)$ & -0.00197 & $(0.766)$ & -0.00242 & $(0.715)$ \\
\hline days w/o change & -0.000884 & $(0.000)$ & -0.000919 & $(0.000)$ & -0.000950 & $(0.000)$ \\
\hline workload & -0.0250 & $(0.148)$ & -0.0472 & $(0.170)$ & -0.00240 & $(0.945)$ \\
\hline tryout Axor & 0.0979 & $(0.000)$ & 0.0817 & $(0.000)$ & 0.0784 & $(0.000)$ \\
\hline tryout Atego & -0.0553 & $(0.002)$ & -0.0552 & $(0.002)$ & -0.0562 & $(0.002)$ \\
\hline French & 0.111 & $(0.109)$ & 0.151 & $(0.029)$ & 0.0671 & $(0.344)$ \\
\hline German & 0.249 & $(0.000)$ & 0.257 & $(0.000)$ & 0.143 & $(0.026)$ \\
\hline Turkish & 0.231 & $(0.017)$ & 0.164 & $(0.089)$ & 0.0282 & $(0.771)$ \\
\hline temperature & -0.00490 & $(0.000)$ & -0.00417 & $(0.001)$ & -0.00406 & $(0.001)$ \\
\hline temperature $^{2}$ & 0.000133 & $(0.000)$ & 0.000130 & $(0.000)$ & 0.000126 & $(0.000)$ \\
\hline humidity & 0.00342 & $(0.000)$ & 0.00349 & $(0.000)$ & 0.00356 & $(0.000)$ \\
\hline hours of sunshine & 0.00281 & $(0.025)$ & 0.00248 & $(0.047)$ & 0.00257 & $(0.039)$ \\
\hline rainfall & -0.0125 & $(0.000)$ & -0.0124 & $(0.000)$ & -0.0124 & $(0.000)$ \\
\hline air pressure & -0.00167 & $(0.001)$ & -0.00166 & $(0.000)$ & -0.00173 & $(0.000)$ \\
\hline Monday & -0.210 & $(0.000)$ & -0.192 & $(0.000)$ & -0.189 & $(0.000)$ \\
\hline Tuesday & -0.186 & $(0.000)$ & -0.168 & $(0.000)$ & -0.163 & $(0.000)$ \\
\hline Wednesday & -0.317 & $(0.000)$ & -0.299 & $(0.000)$ & -0.295 & $(0.000)$ \\
\hline Thursday & -0.203 & $(0.000)$ & -0.185 & $(0.000)$ & -0.180 & $(0.000)$ \\
\hline Friday & -0.287 & $(0.000)$ & -0.268 & $(0.000)$ & -0.264 & $(0.000)$ \\
\hline constant & -7.96 & $(0.000)$ & -7.97 & $(0.000)$ & -7.97 & $(0.000)$ \\
\hline $\begin{array}{l}\text { Inverse Mills } \\
\text { Ratio young }\end{array}$ & & & 0.215 & $(0.000)$ & 0.217 & $(0.000)$ \\
\hline $\begin{array}{l}\text { Inverse Mills } \\
\text { Ratio old }\end{array}$ & & & 0.313 & $(0.000)$ & 0.302 & $(0.000)$ \\
\hline adj. $R^{2}$ & 0.041 & & 0.042 & & 0.044 & \\
\hline
\end{tabular}

In the lower right chart, the weighted sum of errors is plotted against average job tenure. Holding average age constant, work teams with longer average job tenure

${ }^{11}$ What we call "pure age effect" here is of course again a composition of other effects that come along 
(i.e. more experience) make fewer errors. For workers who grow old in the plant, the productivity enhancing effect of growing experience (job tenure) compensates the detrimental "pure" age effect so that the overall age profile is rather flat.

Table 1 also displays the coefficients on a wealth of control variables. The second part of Table 1 (on page 15) contains coefficients on the interactions of these control variables with age. The marginal effects of these variables at ages 20, 40, 50, and 60 are given in Table B.2 in Appendix B.

As the focus of this paper is on the relation between productivity and age, we only comment on some interesting interaction effects of age with these variables.
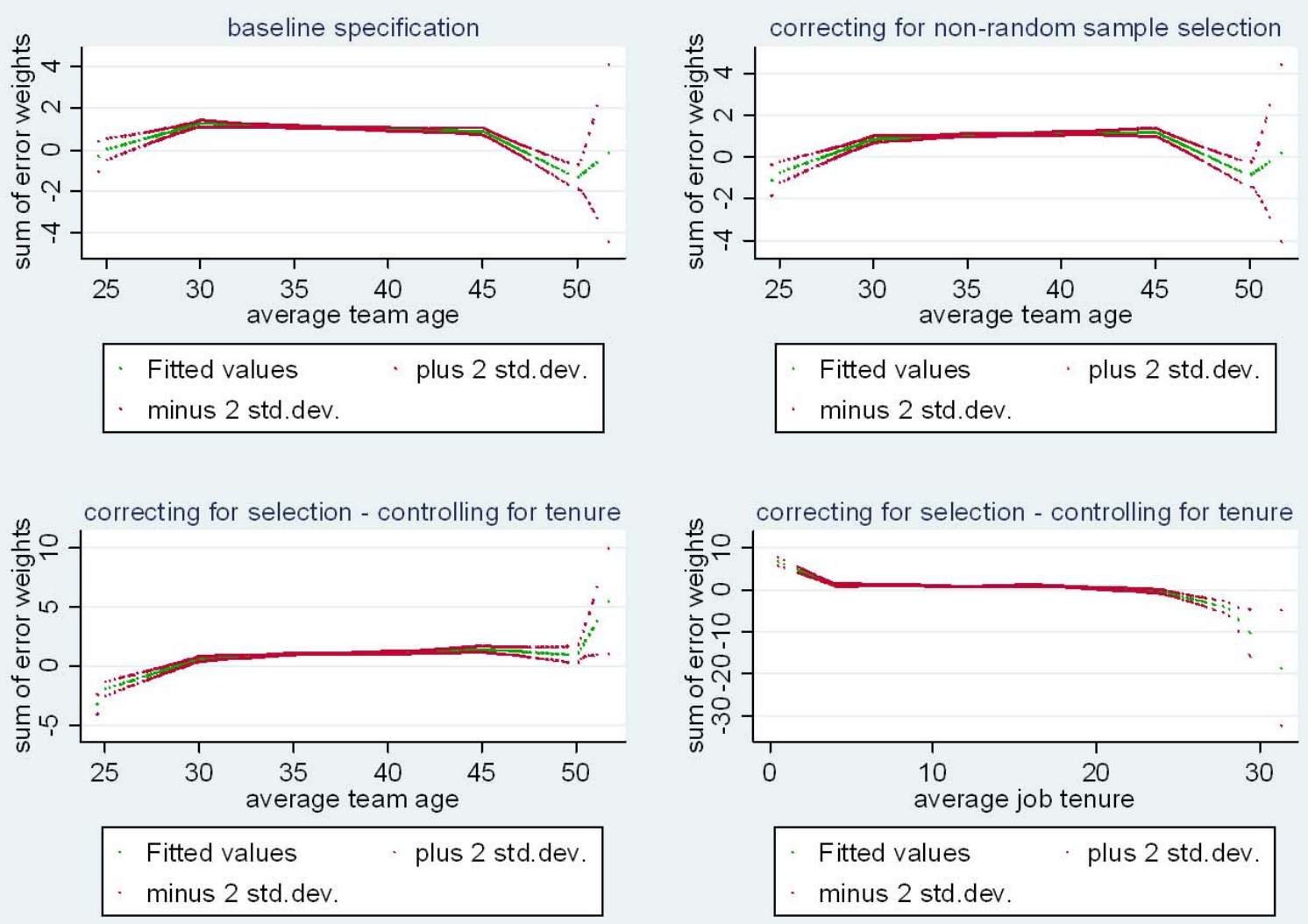

Figure 15: Age productivity profiles on the team level (in terms of errors)

Up to an age of 35, the average number of schooling years has a negative effect on productivity. Presumably, workers who have spent long time in school are overqualified for and bored of the tasks on the assembly line. This effect dies away (and even reverses) as workers grow older. A higher share of workers having a car specific education is good for productivity at least for young workers. This effect also wears

with age like deteriorating health, declining cognitive abilities, etc. 
out (and reverses) as worker age. It should be noted here, that the interaction with age might also reflect differences between cohorts rather than age-specific differences. School education and vocational training have changed over time and the interaction effects might reflect these differences. In Section 4.2, we discuss the problem of distinguishing between age and cohort effects.

A higher share of women in the work team is bad for productivity in young teams and good in old teams. On explanation for this finding is that women make fewer errors but young male workers get distracted (and make more errors) if women are in the team.

The presence of external workers improves productivity; presumably because these "team hoppers" are more experienced. This effect wears out in older teams where additional experience has less benefit.

In large work teams, the sum of error weights is larger. Reasons for this effect may be lower team cohesion and impeded communication. Older workers seem to have more problems with large work teams.

The weighted sum of errors is larger during the early shift. Working early in the morning seems even harder for older workers.

Fluctuation (inversely measured as "days without change in the team composition) seams to affect only older workers productivity adversely.

Excess workload leads to more errors. This effect is less pronounced in older work teams. It seems that experience helps in tense situations.

\subsection{Regressions on the individual level}

In this subsection, we present results from regressions where we use individual worker-days as unit of observation. Even though, we observe errors only on the team level, regressions on the individual level are worthwhile. More concretely, it has three advantages to look at the individual level:

1. Dealing with the distinction between cohort effects and age effects becomes possible.

2. Dealing with sample selection is easier and more powerful.

3. We can look at higher ages.

Identifying age effects on the individual level is possible, because workers move a lot between work teams. Figure 14 displays the distribution of the number of 
work teams that workers work in during our observation period of four years. This movement of workers across work teams allows us to identify worker fixed effects in addition to work team fixed effects.

Worker fixed effects remove differences between workers that are constant over time. This implies that cohort effects (which are just one form of differences between workers (of different cohorts) that are constant over time) are removed. The remaining variation can be due to age effects and time effects. Time effects are unlikely as within the observation period, there have not been any changes in technology or organization in the plant. The tasks have not changed and are absolutely comparable across time. Thus, we conclude that the effects we find are age effects.

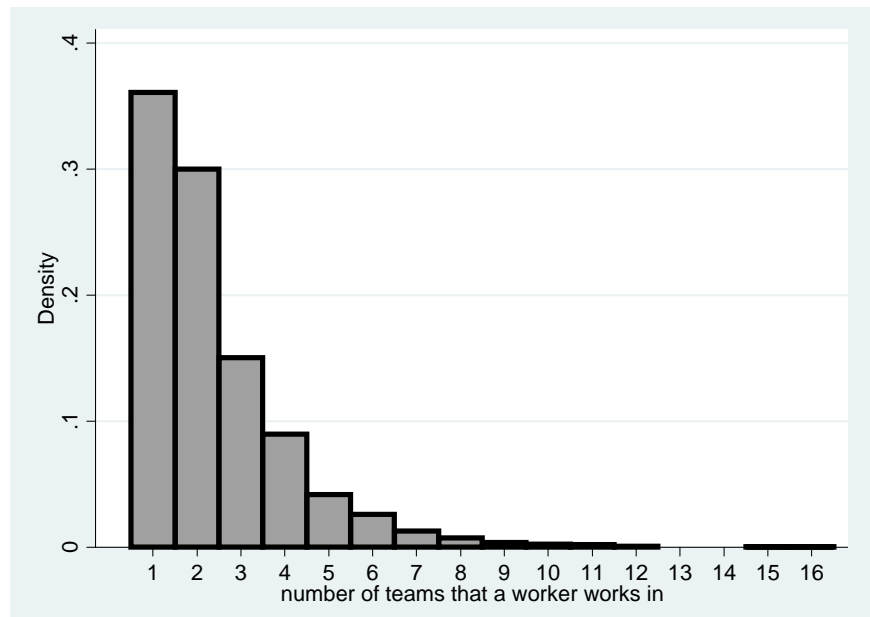

Figure 14: Distribution of the number of teams that a workers works in over time

Worker fixed effects also help remove sample selection bias. If selection into the sample is related to differences in productivity between workers that are constant over time, then the bias the results from this non-random selection is removed as we estimate our coefficients on the variation within workers over time which is not affected by this bias.

On the work team level, the 5 percent oldest team observations (4,784 obs.) have an average age between 45 and 51 years. The 5 percent oldest individual observations (83,802 obs.) have an age between 54 and 65 years. On the individual level, we have thus the possibility to estimate an age productivity profile that ranges from 18 years to 65 years. ${ }^{12}$

Table 2 reports results from regressions on the individual level. Due to con-

${ }^{12}$ From age 60 on, standard errors become quite large. 
straints regarding computing power and memory, we do not include interactions with age in this regression and only the most important controls. We cannot control for job tenure here as on the individual level, age and job tenure are perfectly collinear. ${ }^{13}$ Age effects are again specified as 5-year-age splines. Figure 15 shows the estimated (inverse) age productivity profiles where productivity is again measured as the sum of error weights per day. After a sharp increase up to the age of 25 , the sum of error weights declines slightly but monotonously up to the age of 60 . Thereafter, the mean prediction still declines but the standard errors become too large so that the decline is not significant.

\section{Table 2: Regression Results (individual level)}

\begin{tabular}{|c|c|c|c|c|c|c|c|c|}
\hline \multicolumn{2}{|c|}{ dependent variable: } & \multicolumn{3}{|c|}{ sum of error weights } & \multirow{2}{*}{\multicolumn{2}{|c|}{ number of errors }} & \multirow{2}{*}{\multicolumn{2}{|c|}{$\begin{array}{c}\text { error intensity } \\
\text { (given an error occurred) }\end{array}$}} \\
\hline & \multicolumn{2}{|c|}{ basic specification } & \multicolumn{2}{|c|}{ correcting for sample selection } & & & & \\
\hline \multicolumn{9}{|l|}{ age splines } \\
\hline $15-20$ years & 0.858 & $(0.000)$ & 0.857 & $(0.000)$ & 0.0690 & $(0.000)$ & 0.142 & $(0.397)$ \\
\hline $20-25$ years & 0.143 & $(0.000)$ & 0.143 & $(0.000)$ & 0.0134 & $(0.000)$ & -0.294 & $(0.000)$ \\
\hline $25-30$ years & 0.0193 & $(0.032)$ & 0.0198 & $(0.039)$ & 0.00517 & $(0.000)$ & -0.340 & $(0.000)$ \\
\hline $30-35$ years & -0.0317 & $(0.000)$ & -0.0310 & $(0.000)$ & 0.0000618 & $8(0.928)$ & -0.324 & $(0.000)$ \\
\hline $35-40$ years & -0.0416 & $(0.000)$ & -0.0452 & $(0.000)$ & 0.000529 & $(0.436)$ & -0.385 & $(0.000)$ \\
\hline $40-45$ years & 0.0216 & $(0.004)$ & 0.0189 & $(0.015)$ & 0.00592 & $(0.000)$ & -0.389 & $(0.000)$ \\
\hline $45-50$ years & -0.0462 & $(0.000)$ & -0.0464 & $(0.000)$ & 0.000917 & $(0.149)$ & -0.433 & $(0.000)$ \\
\hline $50-55$ years & 0.0136 & $(0.087)$ & 0.0116 & $(0.048)$ & 0.00484 & $(0.000)$ & -0.422 & $(0.000)$ \\
\hline $55-60$ years & -0.0314 & $(0.104)$ & -0.0557 & $(0.017)$ & -0.00168 & $(0.380)$ & -0.402 & $(0.000)$ \\
\hline $60-65$ years & -0.0564 & $(0.455)$ & -0.0484 & $(0.523)$ & -0.000256 & $(0.967)$ & -0.195 & $(0.423)$ \\
\hline \multicolumn{9}{|l|}{ control variables } \\
\hline workload & 0.371 & $(0.000)$ & 0.371 & $(0.000)$ & 0.0320 & $(0.000)$ & -0.388 & $(0.000)$ \\
\hline workload ${ }^{2}$ & -0.270 & $(0.000)$ & -0.270 & $(0.000)$ & -0.0208 & $(0.000)$ & 1.06 & $(0.000)$ \\
\hline team size & 0.601 & $(0.000)$ & 0.0601 & $(0.000)$ & 0.08388 & $(0.000)$ & 0.0385 & $(0.015)$ \\
\hline$(\text { team size })^{2}$ & -0.00126 & $(0.000)$ & -0.00126 & $(0.000)$ & -0.0000772 & $2(0.000)$ & 0.000451 & $(0.351)$ \\
\hline external & 0.0393 & $(0.007)$ & 0.0388 & $(0.008)$ & 0.00485 & $(0.000)$ & -0.133 & $(0.000)$ \\
\hline late shift & -0.100 & $(0.000)$ & -0.100 & $(0.000)$ & -0.00838 & $(0.000)$ & 0.107 & $(0.000)$ \\
\hline \multicolumn{3}{|c|}{ days w/o change $-0.000854(0.000)$} & \multicolumn{2}{|c|}{$-0.000851(0.000)$} & -0.000951 & $(0.000)$ & 0.00315 & $(0.000)$ \\
\hline tryout Axor & -0.147 & $(0.000)$ & -0.147 & $(0.000)$ & -0.0142 & $(0.000)$ & 0.111 & $(0.001)$ \\
\hline tryout Atego & 0.0334 & $(0.000)$ & 0.0335 & $(0.009)$ & 0.00610 & $(0.000)$ & -0.174 & $(0.000)$ \\
\hline Monday & 1.13 & $(0.000)$ & 1.13 & $(0.000)$ & 0.108 & $(0.000)$ & -1.41 & $(0.000)$ \\
\hline Tuesday & 1.10 & $(0.000)$ & 1.10 & $(0.000)$ & 0.103 & $(0.000)$ & -1.33 & $(0.000)$ \\
\hline Wednesday & 1.36 & $(0.000)$ & 1.36 & $(0.000)$ & 0.124 & $(0.000)$ & -1.38 & $(0.000)$ \\
\hline Thursday & 1.03 & $(0.000)$ & 1.03 & $(0.000)$ & 0.098 & $(0.000)$ & -1.40 & $(0.000)$ \\
\hline Friday & 1.09 & $(0.000)$ & 1.09 & $(0.000)$ & 0.105 & $(0.000)$ & -1.28 & $(0.000)$ \\
\hline \multicolumn{3}{|l|}{$\begin{array}{l}\text { Inverse Mills } \\
\text { Ratio young }\end{array}$} & 0.0125 & $(0.883)$ & 0.000823 & $(0.907)$ & -0.319 & $(0.123)$ \\
\hline \multicolumn{3}{|l|}{$\begin{array}{l}\text { Inverse Mills } \\
\text { Ratio old }\end{array}$} & 0.157 & $(0.060)$ & 0.00799 & $(0.246)$ & 0.389 & $(0.054)$ \\
\hline adj. $R^{2}$ & \multicolumn{2}{|l|}{0.439} & \multicolumn{2}{|l|}{0.439} & \multicolumn{2}{|l|}{0.520} & \multicolumn{2}{|l|}{0.036} \\
\hline \# observations: & \multicolumn{2}{|l|}{$1,676,030$} & \multicolumn{2}{|l|}{$1,676,030$} & \multicolumn{2}{|l|}{$1,676,030$} & \multicolumn{2}{|l|}{150,772} \\
\hline
\end{tabular}

\footnotetext{
${ }^{13}$ Even with non-linear specifications the problem of multi-collinearity is too big.
} 
The second column in Table 2 and the upper right panel of Figure 15 show the results for the regression where-in addition to worker fixed effects-we correct for non-random sample selection by including inverse Mills ratios from the selection equation (see Appendix C 3). The results are virtually unchanged indicating that the worker fixed effects essentially remove the selection bias.

In columns 3 and 4 of Table 2, we decompose our productivity measure in the frequency of errors (how likely is it that an error occurs) and the severity of errors (given that an error occurred). For the frequency of errors, we find a clearly increasing profile: Older workers make significantly more errors. This can also be seen in Figure 16. On the other hand, the severity of errors is strongly decreasing with age (see Figure 17).
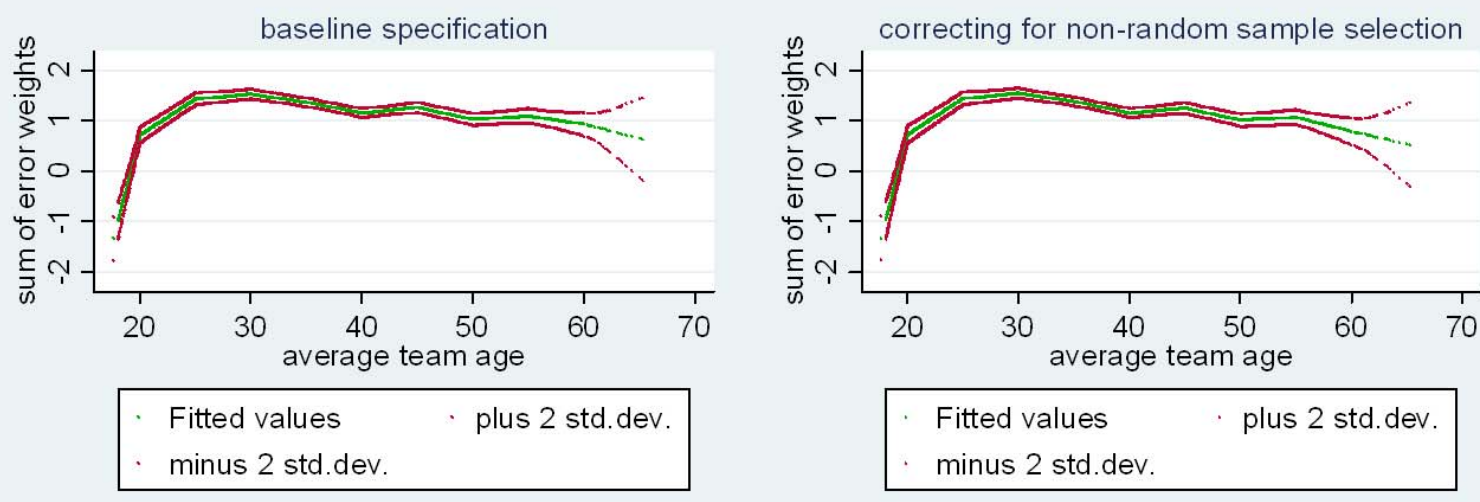

Figure 15: Age productivity profiles on the individual level (in terms of errors)

Our interpretation of these results is as follows: Errors are rare. They usually happen in special (tense) situations when maybe something went wrong and there is little time to fix it and do the regular tasks. In these situations, older more experienced workers seem to know better, which (severe) errors to avoid by all means. This concentration on the vital tasks secures that older workers perform better also in terms of our overall productivity measure sum of error weights. 

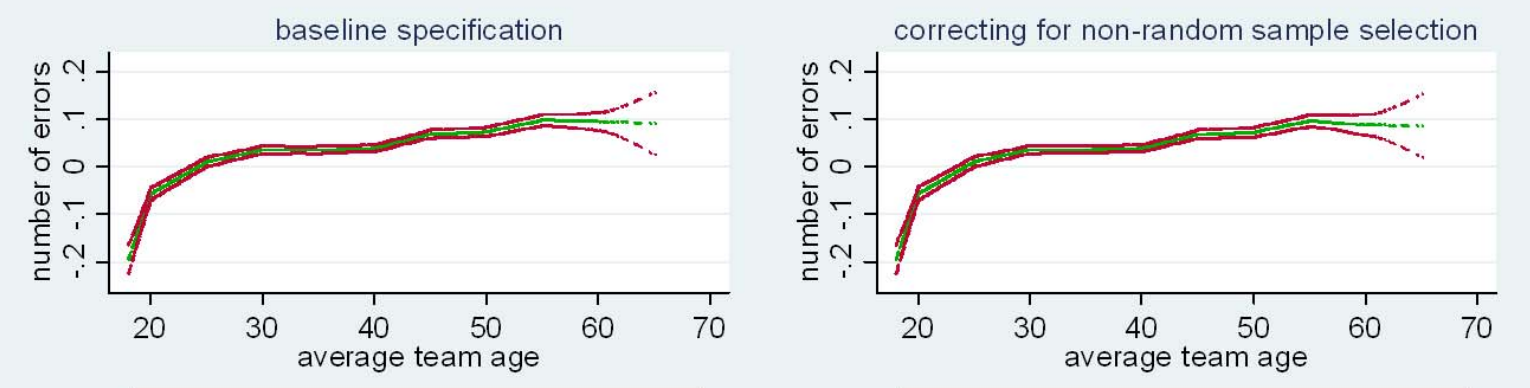

Fitted values plus 2 std. dev.
minus 2 std.dev.

Fitted values plus 2 std.dev. minus 2 std.dev.

Figure 16: Age profiles for the frequency of errors
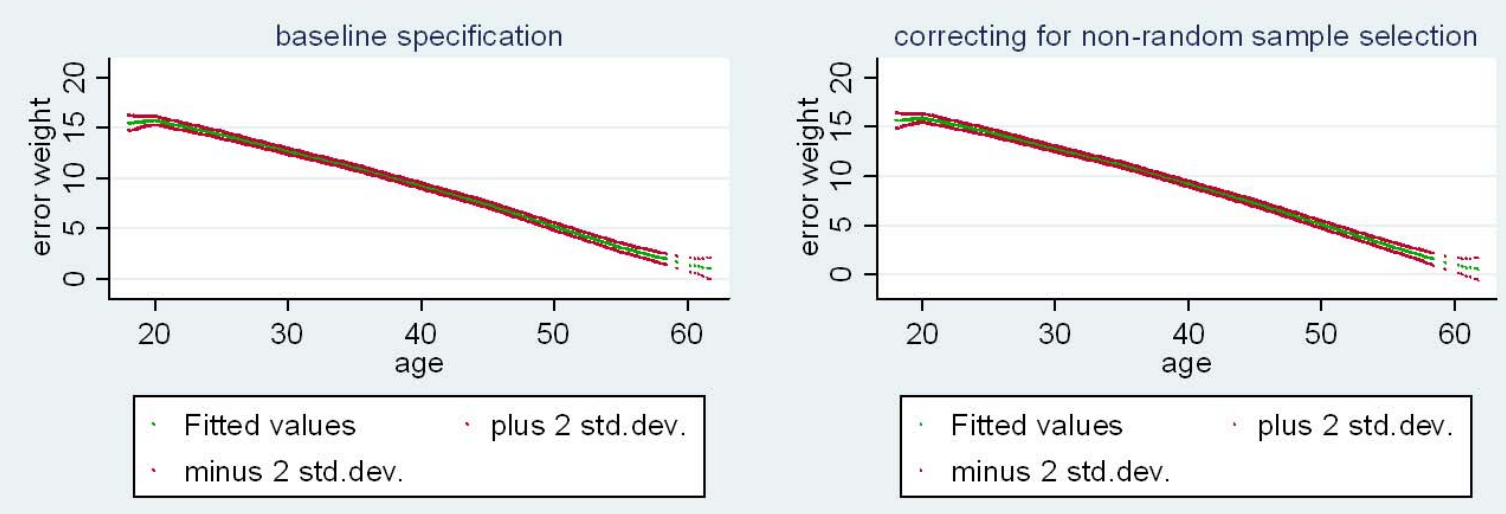

Figure 17: Age profiles for the severity of errors

\section{Conclusion}

We study the relation between the age structure of work teams and their performance in an assembly plant of a car manufacturer. We use data on errors made in the production process to construct our (inverse) productivity measure. As the production quantity is given by the speed of the assembly line, which is equal across all work places, work teams that are differently productive only differ in the errors they make. From these quality data, we know for all 100 work teams the number and severity of errors they made on any day in 2003 through 2006. We combine these data with data from the personnel department that gives us the daily composition of work teams with personal characteristics of the workers. In addition, we have information on the daily work load. 
Controlling for individual worker fixed effects allows us to correct for sample selection bias. In addition, it prevents us from confounding age and cohort age effects. Controlling for work team fixed effects guarantees that the remaining variation we use to estimate the age productivity profile is exogenous: The fluctuation in the worker composition within work teams over time is random. This fluctuation is due to sick leave, vacation and the compensation for overtime and does not leave any room for optimization.

Our findings suggest that productivity is highest among the workers below 30 years of age. For workers older than 30 years, the age productivity profile is fairly stable (slightly increasing if anything). A decomposition into the effect of job tenure and a "pure age effect" reveals that it is indeed job tenure that keeps older workers productivity from falling. A decomposition of our productivity measure into the frequency of errors and error severity shows that the older workers' competence is their ability to avoid especially severe errors. While older workers are slightly more likely to make errors, they hardly make any severe errors. The results suggest that older workers are especially able to grasp difficult situations and then concentrate on the vital tasks.

The huge data set and the truly exogenous variation in team composition enable us to estimate age productivity profiles quite precisely. In addition, we are able to correct potential sample selection bias. On the other hand, our results refer to a single plant only. However, we believe that our results are of general interest. Regarding our estimates of the age-productivity profile, we find it interesting that even at the assembly line-where labor is physically demanding and experience should be comparatively unimportant as tasks are rather simple and do not require substantial training-productivity does not decline at older ages. 


\section{Appendix}

\section{A Descriptive statistics}

Table A.1: Descriptive statistics of the variables used in the regressions

\begin{tabular}{|c|c|c|c|c|c|}
\hline Variable & Mean & Median & Min & $\operatorname{Max}$ & Std. Dev. \\
\hline Date & Jan $29^{\text {th }} 2005$ & Dec $20^{\text {th }} 2004$ & Jan $7^{\text {th }} 20$ & Dec $20^{\text {th }}$ & \\
\hline \# errors & 0.0895 & 0 & 0 & 8 & 0.598 \\
\hline error intensity & 11 & 10 & 0 & 95 & 5.7 \\
\hline weighted sum of errors & 0.984 & 0 & 0 & 135 & 5.73 \\
\hline individual age & 37.1 & 36.9 & 17.5 & 65.2 & 10.5 \\
\hline average team age & 37.1 & 36.8 & 23 & 51.7 & 4.33 \\
\hline individual job tenure & 11.7 & 10.7 & 0 & 39.4 & 9.92 \\
\hline average team tenure & 11.7 & 11.2 & 0.0865 & 31.3 & 4.55 \\
\hline female dummy & 0.0418 & 0 & 0 & 1 & 0.208 \\
\hline share of women & 0.0418 & 0 & 0 & 0.554 & 0.0662 \\
\hline ind. years of schooling & 11.3 & 11 & 9 & 20 & 2.16 \\
\hline av. years of schooling & 11.3 & 11.3 & 9 & 16.6 & 0.826 \\
\hline dummy for technical training & 0.367 & 0 & 0 & 1 & 0.482 \\
\hline share of workers with technical training & 0.367 & 0.364 & 0 & 1 & 0.16 \\
\hline dummy for car specific training & 0.254 & 0 & 0 & 1 & 0.434 \\
\hline share of workers with car specific training & 0.254 & 0.222 & 0 & 1 & 0.183 \\
\hline team size & 14.4 & 14 & 4 & 36 & 4.44 \\
\hline German dummy & 0.653 & 1 & 0 & 1 & 0.473 \\
\hline share of Germans & 0.653 & 0.662 & 0 & 1 & 0.163 \\
\hline French dummy & 0.26 & 0 & 0 & 1 & 0.434 \\
\hline share of French & 0.26 & 0.25 & 0 & 1 & 0.155 \\
\hline Turkish dummy & 0.0410 & 0 & 0 & 1 & 0.192 \\
\hline share of Turkish & 0.0410 & 0 & 0 & 0.418 & 0.0532 \\
\hline dummy for external workers & 0.0718 & 0 & 0 & 1 & 0.235 \\
\hline share of external workers & 0.0718 & 0.0594 & 0 & 1 & 0.0859 \\
\hline individual inverse Mills ratio young & 0.297 & 0.204 & 0 & 3.19 & 0.354 \\
\hline team inverse Mills ratio young & 5.34 & 4.63 & 0 & 20.1 & 3.33 \\
\hline individual inverse Mills ratio old & 0.098 & 0 & 0 & 3.21 & 0.172 \\
\hline team inverse Mills ratio old & 1.76 & 1.37 & 0 & 12.3 & 1.32 \\
\hline \# days without change in team composition & 10.2 & 4 & 1 & 200 & 15.4 \\
\hline dummy for late shift & 0.489 & 0 & 0 & 1 & 0.5 \\
\hline dummy for Axor tryout & 0.0634 & 0 & 0 & 1 & 0.244 \\
\hline dummy for Atego tryout & 0.0651 & 0 & 0 & 1 & 0.247 \\
\hline excess work load & 0.0163 & 0.0291 & -0.458 & 0.826 & 0.134 \\
\hline max temperature $\left(\mathrm{C}^{\circ}\right)$ & 17.6 & 18 & -6.8 & 40.2 & 9.5 \\
\hline air humidity (\%) & 75.2 & 76 & 31 & 99 & 14.3 \\
\hline hours of sunshine & 5.75 & 5.3 & 0 & 15.1 & 4.57 \\
\hline precipitation (mm) & 2.15 & 0 & 0 & 76.5 & 6.12 \\
\hline air pressure $(\mathrm{hPa})$ & 1000.4 & 1000.5 & 968.5 & 1022.3 & 7.35 \\
\hline
\end{tabular}




\section{B Significance tests for marginal effects}

In this appendix, we report tests on the significance of the gradient of the age variables as well as some control variables. Table B.1 reports the test results for the regressions presented in Table 1 . These regressions include a set of interactions with age. The regression equation is given by

$$
\text { sum of errorweights }=\beta_{0}+\sum_{a=20}^{50} \beta_{a, a+5} \cdot \text { AgeSpline }_{a, a+5}+\sum_{k} \beta_{k} \cdot x_{k}+\sum_{k} \beta_{\text {age }, k} \cdot x_{k} \cdot \text { AverageAge }+\mathcal{E}
$$

where subscripts for work teams and days are omitted for the sake of clarity. $x_{k}$ are the control variables. and $x_{k}$.AverageAge are interactions of these control variables with average team age.

The gradient the errors-age-profile (evaluated at sample means) is thus the linear combination of the coefficients on the interactions (where coefficients on interaction terms are multiplied by the sample means of the respective variables) and the coefficient on the respective age spline. The gradient of the error-age profile at age 37 is for example given by:

$$
\left.\frac{\partial(\text { sum of errorweights })}{\partial \text { AverageAge }}\right|_{\text {AverageAge }=37}=\beta_{35-40}+\sum_{k} \beta_{\text {age }, k} \cdot \overline{x_{k}}
$$

where $\overline{x_{k}}=\frac{1}{I \cdot T} \cdot \sum_{i}^{I} \sum_{t}^{T} x_{k i t}$ is the sample mean of variable $x_{k}$. These gradients and their significance levels are reported in Table B.1.

\section{Table B.1: Age gradients}

\begin{tabular}{lll}
\hline $20-25$ years & 0.915 & $(0.225)$ \\
$25-30$ years & 0.316 & $(0.000)$ \\
$30-35$ years & 0.0380 & $(0.061)$ \\
$35-40$ years & 0.0221 & $(0.130)$ \\
$40-45$ years & 0.00791 & $(0.699)$ \\
$45-50$ years & -0.415 & $(0.000)$ \\
$50-55$ years & 0.640 & $(0.613)$ \\
\hline
\end{tabular}

Gradients are calculated from coefficients in the second column of Table 1. $p$-values are in brackets.

Table B.2 reports the marginal effects of selected control variables at different ages.

Table B.2: Marginal effects of control variables at different ages 


\begin{tabular}{lcccccccc}
\hline & $\begin{array}{c}\text { years of } \\
\text { schooling }\end{array}$ & $\begin{array}{c}\text { car specific } \\
\text { training }\end{array}$ & $\begin{array}{c}\text { share of } \\
\text { women }\end{array}$ & $\begin{array}{c}\text { share of team } \\
\text { hoppers }\end{array}$ & team size & late shift & $\begin{array}{c}\text { days without } \\
\text { change }\end{array}$ & $\begin{array}{c}\text { excess } \\
\text { workload }\end{array}$ \\
\hline \multirow{2}{*}{20 years } & 1.36 & -1.42 & 9.79 & -1.58 & 0.103 & -0.0712 & 0.0149 & 3.44 \\
& $(0.000)$ & $(0.023)$ & $(0.000)$ & $(0.039)$ & $(0.001)$ & $(0.549)$ & $(0.001)$ & $(0.000)$ \\
\multirow{5}{*}{ 30 years } & 0.656 & -0.435 & 3.78 & -1.31 & 0.156 & -0.0909 & 0.00570 & 2.97 \\
& $(0.000)$ & $(0.167)$ & $(0.000)$ & $(0.001)$ & $(0.000)$ & $(0.109)$ & $(0.021)$ & $(0.000)$ \\
40 years & -0.0519 & 0.551 & -2.24 & -1.04 & 0.209 & -0.111 & -0.00349 & 2.50 \\
& $(0.270)$ & $(0.021)$ & $(0.000)$ & $(0.000)$ & $(0.000)$ & $(0.001)$ & $(0.048)$ & $(0.000)$ \\
50 years & -0.760 & 1.53 & -8.25 & -0.763 & 0.262 & -0.130 & -0.0127 & 2.02 \\
& $(0.000)$ & $(0.003)$ & $(0.000)$ & $(0.171)$ & $(0.000)$ & $(0.136)$ & $(0.000)$ & $(0.000)$ \\
60 years & -1.47 & 2.52 & -14.3 & -0.490 & 0.316 & -0.150 & -0.0219 & 1.55 \\
& $(0.000)$ & $(0.003)$ & $(0.000)$ & $(0.610)$ & $(0.000)$ & $(0.322)$ & $(0.000)$ & $(0.036)$ \\
\hline Gradients are calculated from coefficients in the second column of Table 1. $p$-values are in brackets.
\end{tabular}

\section{Sample selection}

\section{C.1 The problem}

Older workers are underrepresented in our sample. This might lead to a bias in the estimation of the age productivity profile if the selection into the sample is non-random with respect to productivity and age. There are two possible mechanisms of sample selection that are related to productivity:

- Early retirement

- Stepping up the career ladder

If those workers who are less motivated, less healthy, and less productive are more likely to retire early then those workers who remain in the sample are a positive selection. Early retirement thus potentially leads to an overestimation of the productivity of older workers relative to younger workers. If workers who are more productive are more likely to be promoted to jobs off the assembly line then those who remain in the sample are a negative selection. Selection due to careers thus potentially leads to an underestimation of the relative productivity of older workers.

We try to correct this sample selection bias in two ways:

1. Worker fixed effects

2. Correction of selection bias à la Heckman (1979)

\section{C.2 Worker fixed effects}

Workers differ in productivity. If sample selection is related to these differences (and 
to age), the estimation of the age productivity profile in a cross section is biased. Controlling for worker fixed effects in the estimation removes the bias that results from differences between workers that are constant over time.

\section{C.3 Correction of selection bias à la Heckman (1979)}

We have non-random selection and the selection is different for old and young. Workers at the assembly line are not a random sample of the working age population. There is selection based on age (which is not a problem) but there is probably also selection based on something correlated with productivity (motivation, etc.). Younger workers may exit the sample if they are good enough to get a job outside the assembly line. Older workers may exit the sample if they are not good enough to keep working.

\section{C.3.1 Different selection for young and old}

We observe a person $i$ at date $t$ if she is still working at the assembly line. Suppose that younger workers $i$ remain in the sample $\left(s^{y}=1\right)$ if some latent variable $z_{i t}^{\prime} \cdot \gamma^{y}+\varepsilon_{i t}$ is positive:

$$
s_{i t}^{y}=1\left[z_{i t}^{\prime} \cdot \gamma^{y}+\varepsilon_{i t}>0\right], \quad \varepsilon_{i t} \sim N(0,1) \text { i.i.d. }
$$

Accordingly, selection for older workers is

$$
s_{i t}^{o}=1\left[z_{i t}^{\prime} \cdot \gamma^{o}+\varepsilon_{i t}>0\right], \quad \varepsilon_{i t} \sim N(0,1) \text { i.i.d. }
$$

For given $z_{i t}$, the workers with high $\varepsilon_{i t}$ are observed. The probability that person $i$ is observed is

$$
P\left(z_{i t}^{\prime} \cdot \gamma+\varepsilon_{i t}>0\right)=P\left(\varepsilon_{i t}>-z_{i t}^{\prime} \cdot \gamma\right) \stackrel{\text { symetry }}{=} P\left(\varepsilon_{i t}<z_{i t}^{\prime} \cdot \gamma\right)=\Phi\left(z_{i t}^{\prime} \cdot \gamma\right)
$$

If a person is observed, the number of errors $y_{i t}$ is given by

$$
y_{i t}=x_{i t}^{\prime} \cdot \beta+u_{i t}
$$

For given $x_{i t}$, individuals with high $u_{i t}$ make more errors. Now, we need an assumption regarding the relation between $u_{i t}$ and the $\varepsilon i t$. We assume that

$$
E\left(u_{i t} \mid \varepsilon_{i t}\right)=\left\{\begin{array}{llll}
\xi^{y} \cdot \varepsilon_{i t} & \Leftrightarrow & i & \text { young } \\
\xi^{o} \cdot \varepsilon_{i t} & \Leftrightarrow & i & \text { old }
\end{array}\right.
$$

Now, what about the conditional means of $u_{i t}$ with respect to the $\varepsilon i t$ ? 


$$
E\left(u_{i t} \mid \varepsilon_{i t}>-z_{i t}^{\prime} \cdot \gamma \forall i\right)=\left\{\begin{array}{llll}
\xi^{y} \cdot E\left(\varepsilon_{i t} \mid \varepsilon_{i t}>-z_{i t}^{\prime} \cdot \gamma^{y}\right) & \Leftrightarrow & i & \text { young } \\
\xi^{o} \cdot E\left(\varepsilon_{i t} \mid \varepsilon_{i t}>-z_{i t}^{\prime} \cdot \gamma^{y}\right) & \Leftrightarrow & i & \text { old }
\end{array}=\left\{\begin{array}{lll}
\xi^{y} \cdot \frac{\phi\left(z_{i t}^{\prime} \cdot \gamma^{y}\right)}{\Phi\left(z_{i t}^{\prime} \cdot \gamma^{\nu}\right)} \Leftrightarrow & i \text { young } \\
\xi^{o} \cdot \frac{\phi\left(z_{i t}^{\prime} \cdot \gamma^{p}\right)}{\Phi\left(z_{i t} \cdot \gamma^{p}\right)} \Leftrightarrow & i \text { old }
\end{array}\right.\right.
$$

What's the expectation of $y_{i t}$ given $x_{i t}$ and $z_{i t}$ such that we observe the worker?

$$
\begin{gathered}
E\left(y_{i t} \mid x_{i t}, s_{i t}=1 \forall i\right)=E\left(y_{i t} \mid x_{i t}, \varepsilon_{i t}>-z_{i t}^{\prime} \cdot \gamma\right)=E\left(x_{i t}^{\prime} \cdot \beta+u_{i t} \mid x_{i t}, \varepsilon_{i t}>-z_{i t}^{\prime} \cdot \gamma\right) \\
E\left(y_{i t} \mid x_{i t}, s_{i t}=1\right)=x_{i t}^{\prime} \cdot \beta+E\left(u_{i t} \mid x_{i t}, \varepsilon_{i t}>-z_{i t}^{\prime} \cdot \gamma\right)
\end{gathered}
$$

The expected value of $y_{i t}$ given that worker $i$ is observed is:

$$
E\left(y_{i t} \mid x_{i t}, s_{i t}=1 \quad \forall i\right)=x_{i t}^{\prime} \cdot \beta+\left\{\begin{array}{l}
\xi^{y} \cdot \frac{\phi\left(z_{i t}^{\prime} \cdot \gamma^{y}\right)}{\Phi\left(z_{i t}^{\prime} \cdot \gamma^{y}\right)} \Leftrightarrow \quad i \text { young } \\
\xi^{o} \cdot \frac{\phi\left(z_{i t}^{\prime} \cdot \gamma^{0}\right)}{\Phi\left(z_{i t}^{\prime} \cdot \gamma^{\circ}\right)} \Leftrightarrow \quad i \quad \text { old }
\end{array}\right.
$$

Equation (11) is estimated where the inverse Mills ratios $\frac{\phi\left(z_{z_{i t}}^{\prime} \cdot \gamma^{\nu}\right)}{\Phi\left(z_{z_{i t}} \cdot \gamma^{\nu}\right)}$ and $\frac{\phi\left(z_{i^{i}}^{\prime} \cdot \gamma^{p}\right)}{\Phi\left(z_{i t}^{\prime} \cdot \gamma^{\nu}\right)}$ are predictions from estimating equation (5) using a probit specification. Results from estimating equation (11) are reported in the central column of Table 1. Results from estimating equation (5) are in Table C.1.

\section{C.3.2 Errors on the team level}

So far, we considered the case where errors and selection are both observed at the individual level. In our data, however, the errors are observed at the team level. This makes correction of the selection bias a bit more complicated. If the team $j$ is observed, the number of errors $y_{i t}$ is given by

$$
y_{j t}=x_{j t}^{\prime} \cdot \beta+u_{j t}
$$

where $x_{i t}$ are team characteristics like average age or share of women. For given $x_{i t}$, teams with high $u_{i t}$ make more errors. Selection of workers into the sample is given by (equation: selection young) and (equation: selection young). Now, we need an assumption regarding the relation between $u_{i t}$ and the $\left\{\varepsilon_{i t}\right\}_{i=1}^{N_{j}}$. We assume that

$$
E\left(u_{j t} \mid \varepsilon_{i t}\right)=\left\{\begin{array}{llll}
\xi^{y} \cdot \varepsilon_{i t} & \Leftrightarrow & i & \text { young } \\
\xi^{o} \cdot \varepsilon_{i t} & \Leftrightarrow & i & \text { old }
\end{array}\right.
$$

and 


$$
E\left(u_{j t} \mid\left\{\varepsilon_{i t}\right\}_{i=1}^{N_{j}}\right)=\xi^{y} \cdot \sum_{i \text { young }} \varepsilon_{i t}+\xi^{o} \cdot \sum_{i \text { old }} \varepsilon_{i t}
$$

This implies that within the young and within the old, each individual eit of any worker $i$ has the same effect on the teams performance. The individual $\varepsilon i t$ are i.i.d. The individual effects just add up.

Now, what about the conditional means of $u_{i t}$ with respect to the $\varepsilon i t$ 's?

$$
\begin{aligned}
E\left(u_{j t} \mid \varepsilon_{i t}>-z_{i t}^{\prime} \cdot \gamma \forall i\right) & =\xi^{y} \cdot \sum_{i \text { young }} E\left(\varepsilon_{i t} \mid \varepsilon_{i t}>-z_{i t}^{\prime} \cdot \gamma^{y} \forall i\right)+\xi^{o} \cdot \sum_{i \text { old }} E\left(\varepsilon_{i t} \mid \varepsilon_{i t}>-z_{i t}^{\prime} \cdot \gamma^{y} \quad \forall i\right) \\
& =\xi^{y} \cdot \sum_{i \text { young }} \frac{\phi\left(z_{i t}^{\prime} \cdot \gamma^{y}\right)}{\Phi\left(z_{i t}^{\prime} \cdot \gamma^{y}\right)}+\xi^{o} \cdot \sum_{i \text { old }} \frac{\phi\left(z_{i t}^{\prime} \cdot \gamma^{o}\right)}{\Phi\left(z_{i t}^{\prime} \cdot \gamma^{o}\right)}
\end{aligned}
$$

What's the expectation of $y_{i t}$ given $x_{i t}$ and $\left\{z_{i t}\right\}_{i=1}^{N}$ such that we observe the team?

$$
\begin{gathered}
E\left(y_{j t} \mid x_{j t}, s_{i t}=1 \forall i\right)=E\left(y_{j t} \mid x_{j t}, \varepsilon_{i t}>-z_{i t}^{\prime} \cdot \gamma \forall i\right)=E\left(x_{j t}^{\prime} \cdot \beta+u_{j t} \mid x_{i t}, \varepsilon_{i t}>-z_{i t}^{\prime} \cdot \gamma \forall i\right) \\
E\left(y_{j t} \mid x_{j t}, s_{i t}=1 \forall i\right)=x_{j t}^{\prime} \cdot \beta+E\left(u_{j t} \mid x_{j t}, \varepsilon_{i t}>-z_{i t}^{\prime} \cdot \gamma \forall i\right)
\end{gathered}
$$

The expected value of $y_{i t}$ given that team $j$ is observed is:

$$
E\left(y_{j t} \mid x_{j t}, s_{i t}=1 \forall i\right)=x_{j t}^{\prime} \cdot \beta+\xi^{y} \cdot \sum_{i \text { young }} \frac{\phi\left(z_{i t}^{\prime} \cdot \gamma^{y}\right)}{\Phi\left(z_{i t}^{\prime} \cdot \gamma^{y}\right)}+\xi^{o} \cdot \sum_{i \text { old }} \frac{\phi\left(z_{i t}^{\prime} \cdot \gamma^{o}\right)}{\Phi\left(z_{i t}^{\prime} \cdot \gamma^{o}\right)}
$$

Equation (18) is estimated where the inverse Mills ratios $\frac{\phi\left(z_{z_{i t}}^{\prime} \cdot \gamma^{\nu}\right)}{\Phi\left(z_{z_{i t}} \cdot \gamma^{\nu}\right)}$ and $\frac{\phi\left(z_{i^{i}}^{\prime} \cdot \gamma^{p}\right)}{\Phi\left(z_{i t}^{\prime} \cdot \gamma^{p}\right)}$ are predictions from estimating equation (5) using a probit specification. Results from estimating equation (18) are reported in the second column of Table 2. Results from estimating equation (5) are in Table C.1.

\section{C.3.3 Estimating the selection equation}

Table C.1 reports results from estimating the selection equation (5) using a probit specification: $P\left(z_{i t}^{\prime} \cdot \gamma+\varepsilon_{i t}>0\right)=\Phi\left(z_{i t}^{\prime} \cdot \gamma\right)$. The left hand column reports the results from the selection equation for the younger workers ( $<40$ years) while the right hand column contains the results for the older workers ( $\geq 40$ years). An important variable that affects the probability of being in the sample but not the number and severity of errors is the individual sickness rate. For every worker, we calculate the average absence rate due to sickness and include it in the selection equation but not in the error regressions. 
Table C.1: Regression results: sample selection

dependent variable: dummy for being in the sample

\begin{tabular}{|c|c|c|c|c|}
\hline \multicolumn{3}{|c|}{ workers younger than 40 years } & \multicolumn{2}{|c|}{ workers older than 40 years } \\
\hline \multicolumn{5}{|l|}{ age dummies } \\
\hline age $<20$ & 0.143 & $(0.239)$ & & \\
\hline $20<$ age $<22$ & 0.130 & $(0.285)$ & & \\
\hline $22<$ age $<24$ & 0.267 & $(0.028)$ & & \\
\hline $24<$ age $<26$ & 0.321 & $(0.008)$ & & \\
\hline $26<$ age $<28$ & 0.503 & $(0.000)$ & & \\
\hline $28<$ age $<30$ & 0.686 & $(0.000)$ & & \\
\hline $30<$ age $<32$ & 0.823 & $(0.000)$ & & \\
\hline $32<$ age $<34$ & 0.924 & $(0.000)$ & & \\
\hline $34<$ age $<36$ & 1.13 & $(0.000)$ & & \\
\hline $36<$ age $<38$ & 1.16 & $(0.000)$ & & \\
\hline $38<$ age $<40$ & 1.10 & $(0.000)$ & & \\
\hline $40<$ age $<42$ & & & 6.58 & $(0.000)$ \\
\hline $42<$ age $<44$ & & & 6.54 & $(0.000)$ \\
\hline $44<$ age $<46$ & & & 6.65 & $(0.000)$ \\
\hline $46<$ age $<48$ & & & 6.56 & $(0.000)$ \\
\hline $48<$ age $<50$ & & & 6.50 & $(0.000)$ \\
\hline $50<$ age $<52$ & & & 6.59 & $(0.000)$ \\
\hline $52<$ age $<54$ & & & 6.63 & $(0.000)$ \\
\hline $54<$ age $<56$ & & & 6.19 & $(0.000)$ \\
\hline $56<$ age $<58$ & & & 5.65 & $(0.000)$ \\
\hline $58<$ age $<60$ & & & 4.54 & $(0.000)$ \\
\hline $60<$ age $<62$ & & & 4.84 & $(0.000)$ \\
\hline $62<$ age $<64$ & & & 6.04 & $(0.000)$ \\
\hline $64<$ age & & & 4.87 & $(0.000)$ \\
\hline average team age & 0.0308 & $(0.000)$ & -0.0516 & $(0.000)$ \\
\hline sickness rate & 0.00641 & $(0.000)$ & -0.00683 & $(0.000)$ \\
\hline years of schooling & 0.0971 & $(0.000)$ & -0.0294 & $(0.000)$ \\
\hline av. team schooling years & 0.0605 & $(0.000)$ & -0.289 & $(0.000)$ \\
\hline German dummy & 1.03 & $(0.000)$ & 0.196 & $(0.000)$ \\
\hline share of Germans & -3.93 & $(0.000)$ & -2.38 & $(0.000)$ \\
\hline French dummy & 1.06 & $(0.000)$ & 0.418 & $(0.000)$ \\
\hline share of French & -5.26 & $(0.000)$ & -3.96 & $(0.000)$ \\
\hline Turkish dummy & 1.45 & $(0.000)$ & 0.259 & $(0.000)$ \\
\hline share of Turkish & -3.61 & $(0.000)$ & -5.13 & $(0.000)$ \\
\hline female dummy & -0.556 & $(0.000)$ & -0.339 & $(0.000)$ \\
\hline share of women & -0.821 & $(0.000)$ & -0.121 & $(0.012)$ \\
\hline late shift & 0.379 & $(0.000)$ & -0.395 & $(0.000)$ \\
\hline team hopper dummy & -0.740 & $(0.000)$ & -1.75 & $(0.000)$ \\
\hline share of team hoppers & -3.30 & $(0.000)$ & -1.56 & $(0.000)$ \\
\hline team size & -0.00659 & $9(0.000)$ & 0.0255 & $(0.000)$ \\
\hline av. team tenure & 0.00438 & $(0.000)$ & 0.0547 & $(0.000)$ \\
\hline PFI & 0.0741 & $(0.000)$ & -0.640 & $(0.000)$ \\
\hline$\overline{R^{2}}$ & 0.247 & & 0.285 & \\
\hline \# observations & 2030939 & & 1164115 & \\
\hline
\end{tabular}




\section{References}

Aubert, P., and B. Crépon (2004): "La productivité des salariés âgés: une tentative d'estimation,” Économie et Statistique, 368, 95 - 119.

Börsch-Supan, A., I. Düzgün, and M. Weiss (2005): "Altern und Produktivität: Zum Stand der Forschung," MEA Discussion Paper, 73-05, http://www.mea.unimannheim.de.

Crépon, B., N. Deniau, and S. Pérez-Duarte (2002): "Wages, Productivity, and Workers Characteristics: A French Perspective," mimeo, Centre de Recherche en Économie et Statistique (CREST) and Institut National de la Statistique et des Études Économiques (INSEE), Paris, France.

Fair, R. (1994): "How Fast Do Old Men Slow Down?," The Review of Economics and Statistics, 76(1), $103-118$.

- (2005a): "Estimated Age Effects in Athletic Events and Chess," mimeo, Cowles Foundation, Yale University, http://fairmodel.econ.yale.edu/.

— (2005b): "Estimated Age Effects in Baseball," mimeo, Cowles Foundation, Yale University, http://fairmodel.econ.yale.edu/.

Frank, R. H., and R. M. Hutchens (1993): "Wage, Seniority, and the Demand for Rising Consumption Profiles," Journal of Economic Behavior and Organization, 21(3), $251-276$.

Galenson, D. W. (2005): "The Greatest Artists of the Twentieth Century," NBER Working Papers, 11899.

Galenson, D. W., and B. A. Weinberg (2000): "Age and the Quality of Work: The Case of Modern American Painters," Journal of Political Economy, 108(4), 671 777.

- (2001): "Creating Modern Art: The Changing Careers of Painters in France from Impressionism to Cubism," The American Economic Review, 91(4), 1063 1071.

Grund, C., and N. Westergård-Nielsen (2005): "Age Structure of the Workforce and Firm Performance," IZA Discussion Paper, 1816. 
Haltiwanger, J. C., J. I. Lane, and J. R. Spletzer (1999): "Productivity Differences Across Employers: The Roles of Employer Size, Age, and Human Capital," The American Economic Review, 89(2), 94-98.

- (2007): "Wages, Productivity, and the Dynamic Interaction of Business and Workers," Labour Economics, forthcoming.

Hellerstein, J. K., and D. Neumark (1995): "Are Earnings Profiles Steeper Than Productivity Profiles? Evidence from Israeli Firm-Level Data," Journal of Human Resources, 30(1), 89- 112 .

- (2004): "Production Function and Wage Equation Estimation with Heterogeneous Labor: Evidence From a New Matched Employer-Employee Data Set," NBER Working Paper, 10325.

Hellerstein, J. K., D. Neumark, and K. R. Troske (1999): "Wages, Productivity, and Worker Characteristics: Evidence from Plant Level Production Function and Wage Equations," Journal of Labor Economics, 17(3), 409 - 446.

Hunter, J. E., and R. F. Hunter (1984): "Validity and Utility of Alternative Predictors of Job Performance," Psychological Bulletin, 96, 72 - 98.

Ilmakunnas, P., and M. Maliranta (2005): "Technology, Labour Characteristics and Wage-Productivity Gaps," Oxford Bulletin of Economics and Statistics, 67(5), $623-645$.

Jones, B. F. (2005): "Age and Great Invention,” NBER Working Paper, 11359.

Kotlikoff, L., and D. Wise (1989): "Employee Retirement and a Firm's Pension Plan," in The Economics of Aging, ed. by D. Wise, pp. 279 - 334. University of Chicago Press, Chicago.

Kotlikoff, L. J., and J. Gokhale (1992): "Estimating a Firm's Age-Productivity Profile Using the Present Value of Workers' Earnings," Quarterly Journal of Economics, 107(4), $1215-1242$.

Laitner, J., and D. Stolyarov (2005): "Technological Progress and Worker Productivity at Different Ages," mimeo, University of Michigan.

Lazear, E. (1979): "Why is There Mandatory Retirement?," Journal of Political Economy, 87(6), $1261-1284$. 
- (1981): "Agency, Earnings Profiles, Productivity, and Hours Restrictions," American Economic Review, 71(4), 606 - 620.

Loewenstein, G., and N. Sicherman (1991): "Do Workers Prefer Increasing Wage Profiles?," Journal of Labor Economics, 9(1), 67 - 84.

Malmberg, B., T. Lindh, and M. Halvarsson (2005): "Productivity Consequences at the Plant Level of Work-Force Ageing: Stagnation or a Horndal Effect?," mimeo, Institute for Future Studies, Stockholm, Sweden.

McEvoy, G. M., and W. F. Cascio (1989): "Cumulative Evidence of the Relationship Between Employee Age and Job Performance," Journal of Applied Psychology, $74(1), 11-17$.

Medoff, J. L., and K. G. Abraham (1980): "Experience, Performance, and Earnings," Quarterly Journal of Economics, 95(4), 703 - 736.

Prskawetz, A., B. Mahlberg, V. Skirbekk, I. Freund, M. W. Dworak, T. Lindh, B. Malmberg, A.-C. Jans, O. S. Nordström, and F. Andersson

- (2005): "The Impact of Population Ageing on Innovation and Productivity Growth in Europe," Vienna Institute of Demography, Austrian Academy of Sciences, Wien, Austria and Institute for Futures Studies, Stockholm, Sweden.

Salthouse, T. A., and T. J. Maurer (1996): “Aging, Job Performance, and Career Development," in Handbook of the Psychology of Aging, 4th Edition, ed. by J. E. Birren, and K. W. Schaie, pp. 353 - 364. Kluwer Academic Publishers, New York.

Schneider, H., and D. Stein (2006): "Personalpolitische Strategien Deutscher Unternehmen zur Bewältigung demografisch bedingter Rekrutierungsengpässe bei Führungskräften,” Research Report 6, IZA, Bonn, Germany.

Skirbekk, V. (2004): “Age and Individual Productivity: A Literature Survey," in Vienna Yearbook of Population Research, ed. by G. Feichtinger, Vienna. Verlag der Österreichischen Akademie der Wissenschaften, Vienna.

Weinberg, B. A., and D. W. Galenson (2005): "Creative Careers: The Life Cycles of Nobel Laureates in Economics,” NBER Working Paper, 11799. 


\section{Discussion Paper Series}

Mannheim Research Institute for the Economics of Aging Universität Mannheim

To order copies, please direct your request to the author of the title in question.

\begin{tabular}{|c|c|c|c|}
\hline Nr. & Autoren & Titel & Jahr \\
\hline $137-07$ & $\begin{array}{l}\text { Hendrik Jürges, } \\
\text { Mauricio Avendano, } \\
\text { Johan Mackenbach }\end{array}$ & $\begin{array}{l}\text { How comparable are different measures of self- } \\
\text { rated health? Evidence from five European } \\
\text { countries }\end{array}$ & 07 \\
\hline $138-07$ & \begin{tabular}{|l} 
Hendrik Jürges, \\
Kerstion Schneider
\end{tabular} & $\begin{array}{l}\text { What can go wrong will go wrong: Birthday } \\
\text { effects and early tracking in the German school } \\
\text { system }\end{array}$ & 07 \\
\hline $139-07$ & Hendrik Jürges & $\begin{array}{l}\text { Does ill health affect savings intentions? } \\
\text { Evidence from SHARE }\end{array}$ & 07 \\
\hline $140-07$ & Hendrik Jürges & $\begin{array}{l}\text { Health inequalities by education, income, and } \\
\text { wealth: a comparison of } 11 \text { European countries } \\
\text { and the US }\end{array}$ & 07 \\
\hline $141-07$ & Hendrik Jürges & $\begin{array}{l}\text { Healthy minds in healthy bodies. An } \\
\text { international comparison of education-related } \\
\text { inequality in physical health among older adults }\end{array}$ & 07 \\
\hline $142-07$ & \begin{tabular}{|l} 
Karsten Hank, \\
Stephanie Stuck
\end{tabular} & $\begin{array}{l}\text { Volunteer Work, Informal Help, and Care among } \\
\text { the } 50+\text { in Europe: Further Evidence for 'Linked' } \\
\text { Productive Activities at Older Ages }\end{array}$ & 07 \\
\hline $143-07$ & Jürgen Maurer & $\begin{array}{l}\text { Assessing Horizontal Equity in Medication } \\
\text { Treatment Among Elderly Mexicans: Which } \\
\text { Socioeconomic Determinants Matter Most? }\end{array}$ & 07 \\
\hline $144-07$ & Jürgen Maurer & $\begin{array}{l}\text { Socioeconomic and Health Determinants of } \\
\text { Health Care Utilization Among Elderly } \\
\text { Europeans: A Semiparametric Assessment of } \\
\text { Equity, Intensity and Responsiveness for Ten } \\
\text { European Countries }\end{array}$ & 07 \\
\hline $145-07$ & Jürgen Maurer & $\begin{array}{l}\text { Modelling socioeconomic and health } \\
\text { determinants of health care use: A } \\
\text { semiparametric approach }\end{array}$ & 07 \\
\hline $146-07$ & $\begin{array}{l}\text { Jérome Adda, James } \\
\text { Banks, Hans-Martin } \\
\text { von Gaudecker }\end{array}$ & $\begin{array}{l}\text { The Impact of Income Shocks on Health: } \\
\text { Evidence from Cohort Data }\end{array}$ & 07 \\
\hline $147-07$ & $\begin{array}{l}\text { Klaus Jäger, } \\
\text { Wolfgang Kuhle }\end{array}$ & $\begin{array}{l}\text { The Optimum Growth Rate for Population } \\
\text { Reconsidered }\end{array}$ & 07 \\
\hline $148-07$ & $\begin{array}{l}\text { Axel Börsch-Supan, } \\
\text { Matthias Weiss }\end{array}$ & $\begin{array}{l}\text { Age and Productivity in Work Teams: Evidence } \\
\text { from the Assembly Line }\end{array}$ & 07 \\
\hline
\end{tabular}

